\title{
EFFECT OF ULTRASOUND AND MICROBUBBLES ON PEG COATED GOLD NANOROD THERMAL THERAPY
}

\author{
by \\ Christine Tarapacki \\ B.Sc. Ryerson University, 2011 \\ Toronto, Canada
}

\begin{abstract}
A thesis
presented to Ryerson University in partial fulfillment of the requirements for the degree of Master of Science in the Program of Biomedical Physics

Toronto, Ontario, Canada, 2014 (C) Christine Tarapacki, 2014
\end{abstract}




\section{Author's Declaration}

I hereby declare that I am the sole author of this thesis. This is a true copy of the thesis, including any required final revisions as accepted by my examiners.

I authorize Ryerson University to lend this thesis to other institutions or individuals for the purpose of scholarly research.

I further authorize Ryerson University to reproduce this thesis by photocopying or by other means, in total or in part, at the request of other institutions or individuals for the purpose of scholarly research.

I understand that my thesis may be made electronically available to the public.

Christine Tarapacki 


\begin{abstract}
Effect of ultrasound and microbubbles on PEG coated gold nanorod thermal therapy and microvascular perfusion

Christine Tarapacki

Master of Science, Biomedical Physics

Ryerson University, 2014.
\end{abstract}

The effectiveness of PEG coated gold nanorod and laser thermal therapy (AuNR+L) depends on gold nanoparticle delivery. The application of ultrasound and microbubbles (USMB) has been shown to enhance drug delivery across cell membranes. This study investigated the effect of the combined treatment of ultrasound and microbubbles with PEG coated gold nanorod thermal therapy on cancer cells. Cells in suspension were exposed to combinations of AuNR, laser, and USMB. Following the treatment, cell viability was assessed with propidium iodide marker and flow cytometry, and with colony assays. Cell death significantly increased when USMB was combined with AuNR+L during laser treatment compared to either treatment on its own, whereas, in the absence of AuNR, NIR laser light had a protective effect on cells exposed to USMB. Generally, USMB induced an additive therapeutic effect on cell viability when combined with AuNR+L. 


\section{Acknowledgements}

First I'd like to thank my supervisor, Dr. Raffi Karshafian, without him, this thesis would have never been completed. His suggestions and encouragement through my many trial and errors have kept my spirits high. I'm really grateful to have a mentor who trusted in my abilities and provided me with countless opportunities.

I'd like to thank my committee members Dr. Carl Kumaradas and Dr. Michael Kolios for their guidance throughout my thesis to help prepare me for the completion of this degree. They have both been very generous with allowing me to use their equipment and lab space. As a vital part of my CAM work I'd like to thank the team at St Michael's Hospital, Dr. Wolfgang Kuebler and Dr. Arata Tabuchi for graciously welcoming me into their lab, training me, guiding me, and allowing me to use their precious intravital microscope. Their willingness to help and accommodate my time-sensitive experiments has been very much appreciated.

Thanks to the gold nanorod team: Yevgeny Davletshin, Amanda Tran, Lior Dubnitzky, Mithunan Modchalingam and Steve Naraine for helping me exhaust possibilities of the effect of the AuNR solution and discuss anything gold nanoparticle related. Many thanks to Eric da Silva for accepting an extra project into his busy schedule and helping me explore ways to quantify gold inside cells at such low concentrations. I also want to extend my gratitude to Elizabeth Berndl for answering my endless cell related questions, to Arthur Worthington for helping with ultrasound calibrations, and to Graham Pearson for helping me with treatment setup modifications.

I'm truly grateful for the support and discussions with the Karshafian team throughout the years. Most notably I want to thank Anna Sorensen for her invaluable help with whatever mini projects I felt needed to get done as well as her dedication and care for the lab. I'm also grateful to Fayruz Kibria, my chicken buddy, who has made the embryo work truly unforgettable.

Last but not least I'd like to thank my family for their constant support and Krzysztof Wawrzyn for believing in me, providing constant motivation and being my rock through the last few years. 


\section{Table of Contents}

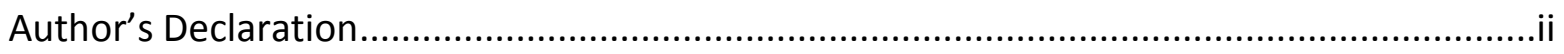

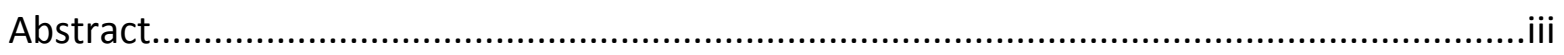

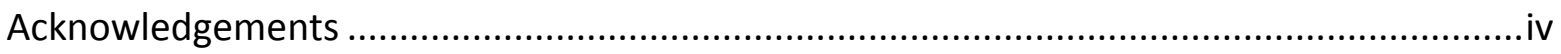

List of Tables .................................................................................................................

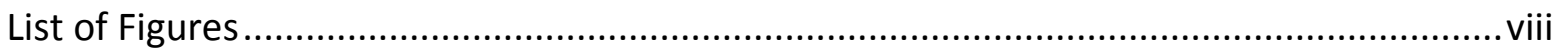

Symbols \& Abbreviations..............................................................................................

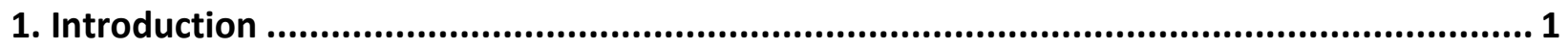

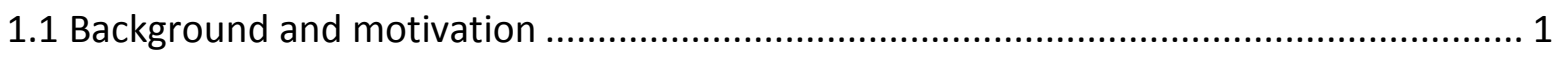

1.2 Gold nanoparticles and photo-thermal therapy ………........................................... 2

1.2.1 Physics of gold nanorod photo thermal therapy ................................................... 2

1.2.2 Biological effects of thermal therapy ...................................................................... 5

1.2.3 Gold nanoparticle toxicity and clinical trials ........................................................ 7

1.3 Ultrasound and Microbubbles ................................................................................. 9

1.3.1 Ultrasound and microbubble physics ............................................................... 9

1.3.2 Ultrasound-microbubbles for targeting drug delivery ............................................ 10

1.3.3 Ultrasound-microbubble bio-effects in vivo ........................................................ 13

1.4 Hypothesis and specific objectives ............................................................................. 15

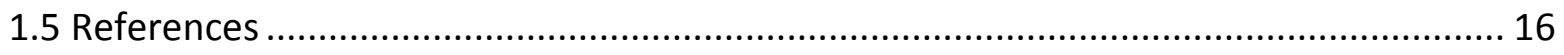

\section{Enhancing laser thermal therapy using PEGylated gold nanoparticles combined with}

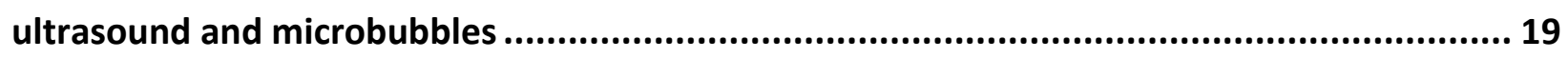

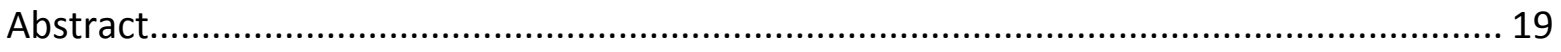

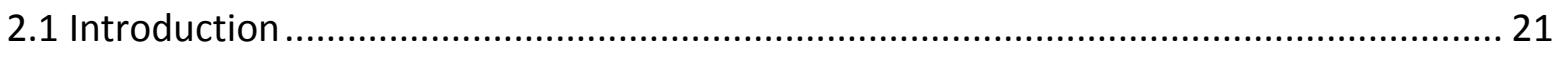

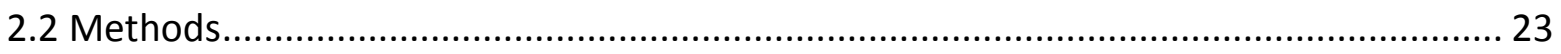

2.2.1 In vitro cell model ............................................................................................ 23

2.2.2 Gold nanoparticles .......................................................................................... 24

2.2.3 Ultrasound-microbubble treatment .................................................................... 25

2.2.4 Thermal treatment and monitoring...................................................................... 26

2.2.5 Viability analysis ............................................................................................... 27 


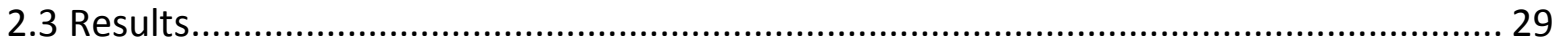

2.3.1 Cells centrifuged before laser ............................................................................ 29

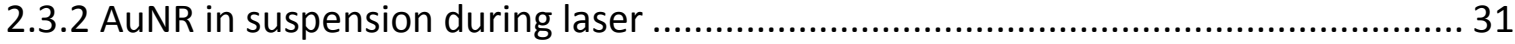

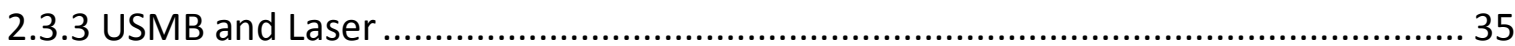

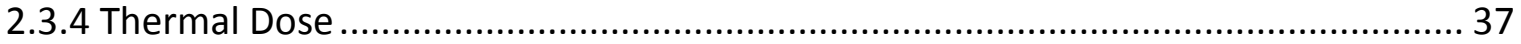

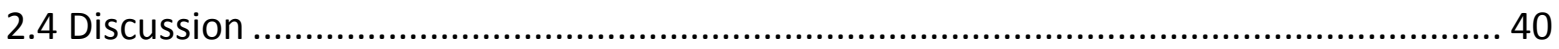

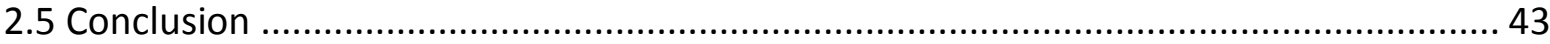

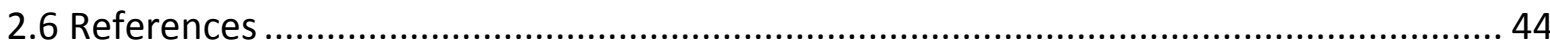

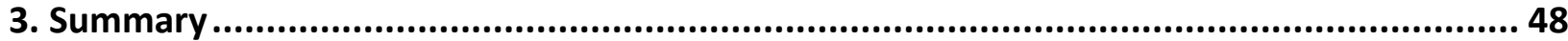

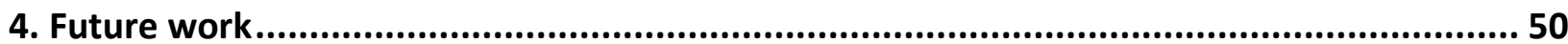

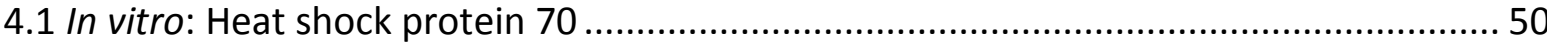

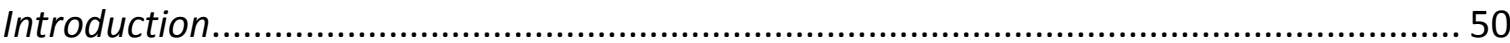

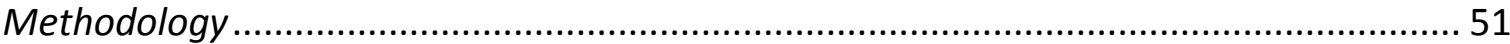

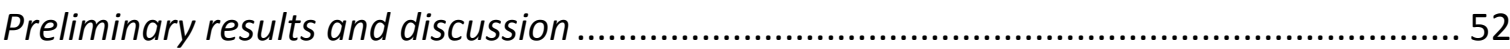

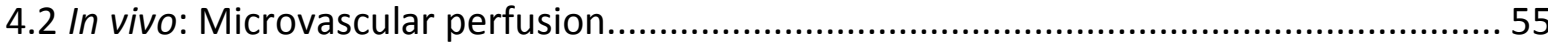

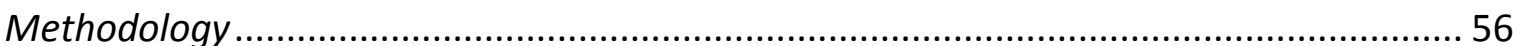

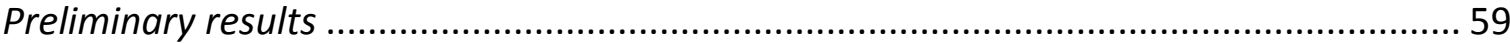

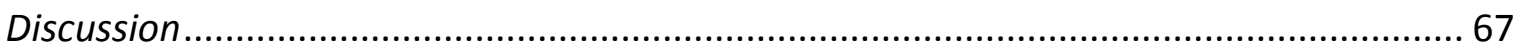

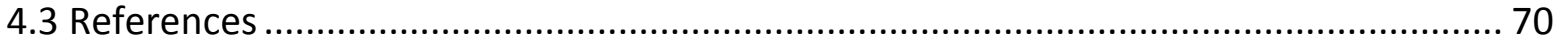




\section{List of Tables}

Table 4.1 Capillary length of CAM treated at $160 \mathrm{kPa}$

Table 4.2 Capillary length of CAM treated at $240 \mathrm{kPa}$

Table 4.3 Capillary length of CAM treated at $320 \mathrm{kPa}$ 


\section{List of Figures}

Figure 1.1 Transverse (A) and longitudinal (B) electron (-) oscillation about the ionic core $(+)$ of a gold nanorod.

Figure 1.2 Process of sonoporation. Microbubbles stimulated by ultrasound waves oscillate resulting in enhanced cell membrane permeability. Drugs can temporarily diffuse across the cell membrane. When the cell membrane reseals the drugs become trapped inside the cell.

Figure 1.3 Ultrasound and microbubble effects on microvasculature. Within the acoustic field microbubbles oscillate and disrupt the surrounding endothelial cells. This allows for drugs such as gold nanorods (AuNR) to leak out of the vessel towards the surrounding cancerous cells.

Figure 2.1 Treatment timeline for the varying treatment combinations of gold nanorod thermal therapy with ultrasound and microbubbles. The time of gold nanorod (AuNR), microbubble (MB) and propidium iodide (PI) addition, ultrasound (US), and laser treatment, centrifuging, and flow cytometry measurements.

Figure 2.2 Ultrasound treatment setup. A signal is generated on a waveform generator, amplified and sent to the ultrasound transducer which is connected to and controlled by a micro-positioning system. The sample chamber has 4 acoustic windows and rests on a magnetic stirrer. Cell suspensions are placed inside and covered with Parafilm.

Figure 2.3 Laser therapy setup. Cell suspensions were placed in a corner well of a 24-well plate and positioned above a laser fiber connected to an $810 \mathrm{~nm}$ continuous wave $(\mathrm{CW})$ diode laser. A thermal camera was positioned perpendicular to the laser 
fiber with a view shown in the insert on the top right corner. The region of interest (ROI) selected was on the bottom of the well and shown in the insert.

Figure 2.4 (A) Propidium iodide viability $\left(\mathrm{V}_{\mathrm{PI}} ; \mathrm{n}=3\right)$ of centrifuged cells prior to laser irradiation assessed through flow cytometry and (B) clonogenic viability $\left(\mathrm{V}_{\mathrm{CA}}\right.$; $\mathrm{n}=9$ ). (AuNR)c $+\mathrm{L}$ represents $3 \times 10^{11} \mathrm{np} / \mathrm{mL}$ of gold nanorods centrifuged prior to laser exposure for 3 minutes at $1.9 \mathrm{~W} / \mathrm{cm}^{2}$, USMB represents ultrasound and microbubbles at $0.6 \mathrm{MPa}$, AuNR+USMB represents $3 \times 10^{11} \mathrm{np} / \mathrm{mL}$ of gold nanorods present during USMB and $(\mathrm{AuNR}+\mathrm{USMB}) \mathrm{c}+\mathrm{L}$ represents samples exposed to AuNR+USMB and centrifuged prior to laser irradiation. A star (*) represents a student t-test significant difference with a $\mathrm{p}<0.05$ and 3 stars $(* * *)$ represents $\mathrm{p}<0.001$.

Figure 2.5 (A) Immediate viability $\left(\mathrm{V}_{\mathrm{PI}} ; \mathrm{n}=9\right)$ and (B) Clonogenic Viability $\left(\mathrm{V}_{\mathrm{CA}}\right.$; $\mathrm{n}=12$ ) of cells exposed to USMB at 0.6 MPa in combination with AuNR and laser. AuNR represents $3 \times 10^{11} \mathrm{np} / \mathrm{mL}$ of gold nanorods present in solution with the cells. One star $(*)$ represents a student t-test significant difference with a $\mathrm{p}<0.05$, two stars $(* *)$ represent $\mathrm{p}<0.001$ and three stars $(* * *)$ represent $\mathrm{p}<0.0001$.

Figure 2.6 (A) Immediate viability $\left(\mathrm{V}_{\mathrm{PI}} ; \mathrm{n}=9\right)$ and (B) Clonogenic Viability $\left(\mathrm{V}_{\mathrm{CA}}\right.$; $\mathrm{n}=12$ ) of cells exposed to USMB at 1.0 MPa in combination with AuNR and laser. AuNR represents $3 \times 10^{11} \mathrm{np} / \mathrm{mL}$ of gold nanorods present in solution with the cells. One star $\left(^{*}\right)$ represents a student t-test significant difference with a $\mathrm{p}<0.05$ and two stars $(* *)$ represent $\mathrm{p}<0.001$.

Figure 2.7 (A) Immediate viability $\left(\mathrm{V}_{\mathrm{PI}} ; \mathrm{n}=9\right)$ and (B) Clonogenic Viability $\left(\mathrm{V}_{\mathrm{CA}}\right.$; $\mathrm{n}=12$ ) of cells exposed to USMB at 0.6 and $1.0 \mathrm{MPa}$ in combination with laser before or after acoustic exposure. One star $(*)$ represents a student t-test significant difference with a $\mathrm{p}<0.05$, two stars $(* *)$ represent $\mathrm{p}<0.001$ and three stars $(* * *)$ represent $\mathrm{p}<0.0001$. 
Figure 2.8 (A). Maximum sample temperature measured with a thermal camera after 3 minutes of laser therapy at $1.9 \mathrm{~W} / \mathrm{cm}^{2}$. (B) Cumulative equivalent minutes at $43^{\circ} \mathrm{C}$ (CEM43) during laser exposure.

Figure 2.9 (A) $V_{P I}$ and (B) $V_{C A}$ relationship with CEM43 for samples containing AuNR at $3 \times 10^{11} \mathrm{np} / \mathrm{mL}$ in suspension during laser treatment with USMB at 0, 0.6 and 1.0 MPa and varying treatment order.

Figure 4.1 (A) Hsp70 for centrifuged samples immediately after treatment and (B) 3 hours after treatment.

Figure 4.2. CAM treatment setup. An ultrasound transducer and objective lens of a fluorescent microscope were confocally aligned and focused on a microvascular region of interest on the CAM. The transducer and bottom of the CAM dish were submerged in a $37^{\circ} \mathrm{C}$ deionized water bath.

Figure 4.3 Vascular perfusion of CAM exposed to $160 \mathrm{kPa}$ for 2 minutes at time 0,1 , 2,5 , and 15 minutes after the start of treatment. ROI is $0.034 \mathrm{~mm}^{2}$.

Figure 4.4 Vascular perfusion of CAM exposed to $240 \mathrm{kPa}$ for 2 minutes at time $1,2,10$, and 15 minutes after the start of treatment. ROI is $0.030 \mathrm{~mm}^{2}$.

Figure 4.5 Micrographs through time after ultrasound and microbubble exposure at $240 \mathrm{kPa}$. Arrows point to vascular blockage which is visible after 10 seconds of ultrasound exposure. White scale bar represents $100 \mu \mathrm{m}$.

Figure 4.6 Vascular perfusion of CAM exposed to $320 \mathrm{kPa}$ for 2 minutes at time 0,1 , 65 2 , and 15 minutes after the start of treatment. ROI is $0.031 \mathrm{~mm}^{2}$. 
Figure 4.7 Capillary perfusion through time due to ultrasound treatment at varying exposure pressure. 


\section{Symbols \& Abbreviations}

\begin{tabular}{ll} 
AuNP & Gold nanoparticle \\
AuNR & Gold nanorod \\
AuNR+L & Gold nanorod laser thermal therapy \\
CAM & Chorioallantoic Membrane \\
CEUS & Contrast enhanced ultrasound \\
CTAB & Cetyltrimethylammonium bromide \\
FBS & Fetal bovine serum \\
Hsp & Heat shock protein \\
Hsp70 & Heat shock protein of size 70 kDa \\
L & Laser \\
mPEG & Methoxypolyethelyne glycol \\
NIR & Near infrared \\
PEG & Polyethelyne glycol \\
PBS & Phosphate buffered saline \\
SPR & Surface Plasmon Resonance \\
USMB & Ultrasound and microbubbles \\
PEG & Polyethelyne glycol \\
PBS & Phosphate buffered saline \\
\hline
\end{tabular}




\section{Introduction}

\subsection{Background and motivation}

Clinical thermal cancer treatments aim to increase the temperature of a target area while minimizing the effect on surrounding normal tissues. Thermal therapy systems include radiofrequency thermal ablation, microwave ablation, high intensity focused ultrasound and laser ablation which are all considered minimally invasive. Typically tissue temperatures are elevated to $40-44^{\circ} \mathrm{C}$ for over 30 minutes to induce tissue damage (Lagendijk, 2000). Due to heat diffusion and non-uniform vascularity, one of the main challenges associated with thermal therapies is creating a localized and homogeneous effect on the target tissue without causing surrounding tissue damage. Nanoparticles made of noble metals such as gold and silver are currently being studied for their efficient absorption properties which can localize the thermal effect (Huang et al., 2006; Link and El-Sayed, 2005; West and Halas, 2003); however, delivering the nanoparticles to regions of interest is still a challenge. This study investigates the possibility of using ultrasonically stimulated microbubbles to localize the delivery of gold nanoparticles into cells through a process called sonoporation which creates transient pores on cell membranes allowing for nanoparticle uptake. 


\subsection{Gold nanoparticles and photo-thermal therapy}

Gold nanoparticles (AuNP) are nano-sized particles with physical dimensions between 1 and $100 \mathrm{~nm}$. Depending on the AuNP properties, they have resonance frequencies that absorb electromagnetic energy and can transfer it to heat their environment. AuNP absorb energy through surface plasmon resonance (SPR) when exposed to light at their resonance frequency resulting in enhanced extinction (absorption + scattering). The SPR peak extinction wavelength is highly dependent on the particle shape and size which can be specifically tuned for thermal or imaging applications.

The main chromophores in the body are melanin, hemoglobin and water (Young, 1997). Biological tissue has an optical window between 600 to $1300 \mathrm{~nm}$ where light has a decreased absorption and can effectively penetrate between 1 and $2 \mathrm{~cm}$ (Anderson and Parrish, 1981; Chang et al., 1999; Smith et al., 2009). By adjusting the physical properties of the nanoparticles (i.e. dimensions, coating composition, surrounding media, etc.), AuNP can be optimized to have SPR peaks within the optical window. This minimizes the absorption in normal tissues and allows for localized heating around the AuNP. Gold nanorods, nanoshells and nanocages can be synthesized to have specific SPR peaks in the therapeutic window but per unit volume the gold nanorods with a peak in the NIR range have the highest absorption efficiency (Jain et al., 2006).

\subsubsection{Physics of gold nanorod photo thermal therapy}

Gold is a noble metal with conduction band electrons that are free to move within the atomic lattice of the metal. The coupling between the electromagnetic field and the oscillating 
conduction electrons are called surface plasmons which enhance the field at the surface interface. Surface plasmon resonance (SPR) occurs when the exposure frequency is resonant with the collective electron oscillations. The electric field of an incoming light wave induces a polarization of free electrons with respect to the ionic core creating a dipole effect. In gold nanoparticles, the mean free path of an electron is $50 \mathrm{~nm}$ and can be larger than the nanoparticle size allowing for electrons to oscillate past the surface of the particle (Kittel and McEuen, 1986; Link et al., 1999)). As seen in Figure 1.1, gold nanorods have 2 resonance frequencies transverse and longitudinal. The peak transverse frequency corresponds to a wavelength of approximately $530 \mathrm{~nm}$ for AuNR smaller than $100 \mathrm{~nm}$, while the peak longitudinal wavelength is red-shifted proportionally to the aspect ratio (length/width) of the rods and can be in the visible or near infrared (NIR) range (Chang et al., 1999; Link and El-Sayed, 2005; Yu et al., 1997).

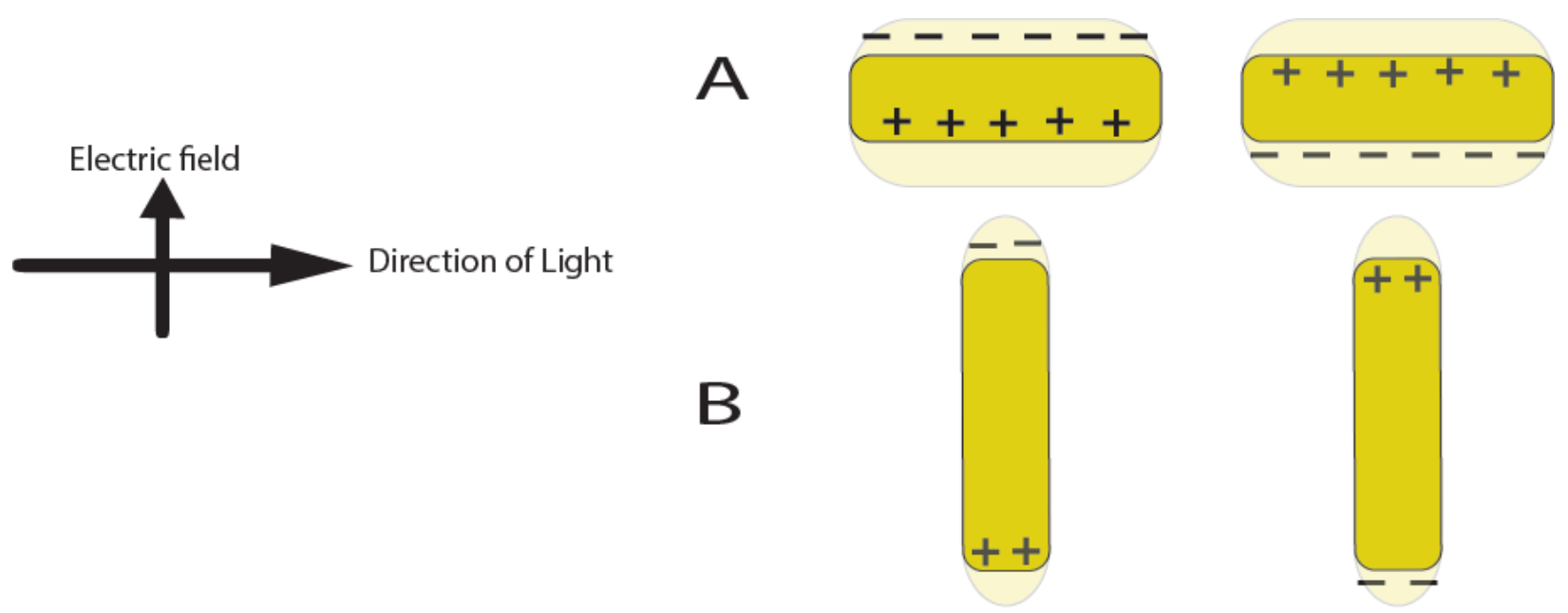

Figure 1.1 Transverse (A) and longitudinal (B) electron (-) oscillation about the ionic core (+) of a gold nanorod. 
Gold nanorods (AuNR) with an aspect ratio of 4 have an SPR peak near $800 \mathrm{~nm}$ which allows for an enhanced light penetration through the body compared to visible light. AuNR have absorption cross sections approximately 4 orders of magnitude higher than other absorption drugs such as Indocyanine Green (Jain et al., 2006), causing fewer nanoparticles to be required for similar thermal effects. The absorption properties of gold nanoparticles are dependent on the metal particle's rigid structure making them less susceptible to photobleaching which is a common problem for conventional dyes (O'Neal et al., 2004). Adjusting the concentration of gold nanoparticles and incident light intensity can create biologically relevant thermal effects.

For a single nanoparticle exposed to light, the heat generated $\left(Q_{\text {nano }}\right)$ is represented by:

$$
Q_{\text {nano }}=C_{a b s} I
$$

where $C_{a b s}\left(\mathrm{~m}^{2}\right)$ is the absorption cross section area of the nanoparticle and $I$ is the local laser fluence $\left(\mathrm{W} / \mathrm{m}^{2}\right)$ (Qin and Bischof, 2012). The absorption cross-section area is dependent on many factors including the particle shape, size, and material, and can be larger than the actual particle size due to the SPR effect (Kelly et al., 2003). $C_{a b s}$ is also a function of the exposure wavelength. With a specific concentration of nanoparticles, $N$ (number of nanoparticles $/ \mathrm{m}^{3}$ ) the heat generated per unit mass, or specific absorption rate $(S A R)$ is the sum of the heat generated from all the nanoparticles and can be represented by:

$$
S A R=N Q_{\text {nano }}=N C_{a b s} I=\mu_{a} I
$$

where $\mu_{a}$ is the absorption coefficient (Qin and Bischof, 2012). 


\subsubsection{Biological effects of thermal therapy}

When normal tissues are heated they respond by vasodilation and increasing blood circulation to dissipate heat (Storm et al., 1979). Temperatures above $42^{\circ} \mathrm{C}$ have previously been shown to decrease blood flow within tumors due to faulty microcirculation and a decreased thermoregulation response compared to normal tissues (Hildebrandt et al., 2002). This causes tumors to have decreased oxygen and nutrient levels and an increased vulnerability to thermal shock (Hildebrandt et al., 2002). However, as a defensive mechanism, cells respond to temperature change by increasing heat shock proteins (Hsp) which protect the cell and sensitive proteins from denaturing (Rylander et al., 2005). Hsp can protect the cells from subsequent thermal shock, radiation, or chemotherapy treatments and increase the chance of tumor recurrence (Rylander et al., 2005). In many cancerous tumors including breast, prostate, colon and hepatocellular cancers, Hsp is overly expressed and may be partially responsible for the cells' survival advantage within the tumor environment (Nylandsted et al., 2000). When thermal therapy is successful it leads to biological effects such as cell membrane blebbing and necrosis (Coakley, 1986; Diederich, 2005).

To determine the fate of a tissue exposed to heat, Sapareto and Dewey's model of thermal dose is often used which compares the exposure temperature and duration to the cumulative equivalent minutes at $43^{\circ} \mathrm{C}$ (CEM43) (Sapareto and Dewey, 1984).

$$
C E M 43=\sum_{i=1}^{N} t_{i} R^{\left(43-T_{i}\right)}
$$


In equation (3), $R$ is the constant of proportionality for the process - typically 0.5 for temperatures above $43^{\circ} \mathrm{C}$ and 0.25 for temperatures below $43^{\circ} \mathrm{C} . T_{i}$ is the temperature in Celsius at the time interval " $i$ " and $t_{i}$ is the time at $T_{i}$ in minutes. CEM43 is expressed in units of equivalent minutes at $43^{\circ} \mathrm{C}$.

When cells uptake gold nanorods through endocytosis, cell death depends on the number of AuNR per cluster and the laser exposure energy. Typically the clusters will localize in endosomes, lysosomes or vacuoles of cells (Chen et al., 2010; Sokolov et al., 2009). Chen et al. (Chen et al., 2010) showed that for a cell with 10-30 AuNR per cluster, energy fluencies larger than $93 \mathrm{~mJ} / \mathrm{cm}^{2}$ led to effective cell death within a very short period of time. A lower energy level required more AuNR per cluster and led to slower cell deterioration (Chen et al., 2010). With a high energy laser pulse, heat is generated within the nanoparticle at a faster rate than can be diffused through tissues. This sudden local heating can create thermal explosions leading to internal cell cavities and damaged cellular structures (Chen et al., 2010; Lukianova-Hleb et al., 2012; Sokolov et al., 2009). The damage can compromise cell membrane integrity and increase permeability. The enhanced permeability due to intercellular AuNR cavitation can be used to enhance uptake of drugs into cells (Lukianova-Hleb et al., 2012; Sokolov et al., 2009). The previously mentioned studies used a biocompatible coating such as polystyrenesulfonate (Chen et al., 2010) or target the cells by coating the nanoparticles with epidermal growth factor or specific cell antigens to encourage cell uptake (Lukianova-Hleb et al., 2012). 


\subsubsection{Gold nanoparticle toxicity and clinical trials}

The safety of nanoparticles depends highly on their surface coating. Previous studies have shown that low concentrations of methoxypolyethelyne glycol (mPEG) coated AuNP have negligible toxicity effects both in vitro and in vivo (Lipka et al., 2010; Niidome et al., 2006; Zhang et al., 2011). The mPEG coating has a nearly neutral surface (zeta potential of approximately $-0.5 \mathrm{mV}$ ) (Niidome et al., 2006) which enhances circulation time in the blood, limits immune system response and minimizes uptake into normal cells (Niidome et al., 2006; Zhang et al., 2011). To take advantage of the low toxicity, previous groups have coated the mPEG-AuNP with transferrin (Chithrani and Chan, 2007; Choi et al., 2010); a molecule with a receptor commonly found in abundance on cancer cell membranes, which triggers endocytosis. Without additional targeted coating, endocytosis of mPEG coated AuNP is very limited (Malugin and Ghandehari, 2010).

Numerous gold nanoparticle toxicity studies have been performed with cells and on animals (Boisselier and Astruc, 2009; Connor et al., 2005; Dobrovolskaia and McNeil, 2007; Gad et al., 2012; Murphy et al., 2008; Niidome et al., 2006; Oberdörster et al., 2007). Although gold is inert and relatively non-toxic, allergic reactions could be caused from long term exposure along with other unknown effects (Wang and Maibach, 2013). A previous study on mice by Gad and colleagues (Gad et al., 2012) reported that even a year after being injected with $150 \mathrm{~nm}$ PEG coated gold nanospheres, the total amount of gold inside a mouse was not significantly different from the initial amount injected. The clearance of nanoparticles is related to their size and charge and in general particles smaller than $6 \mathrm{~nm}$ can easily be filtered through the kidneys (Longmire et al., 2008). 
Currently phase 1 clinical trials are being performed by Nanospectra, a nanoparticle company in Houston, Texas, USA, using gold nanoshells to treat patients with head, neck, and lung cancers (Nanospectra Biosciences, Inc., 2013). The studies are using the well-known enhanced permeability and retention effect present in most solid tumors where the vasculature is leakier, and allows for the accumulation of nano-sized particles. In contrast, normal vasculature has tight junctions preventing nanoparticle leakage into the intercellular space. Exposing the tumor to NIR light either interstitially or extra-corporally, the nanoparticles become activated and cause thermal damage to the nanoparticle filled tumor area.

Delivering high concentrations of AuNP into only target regions, such as inside cancer cells, can be a challenge and result in nanoparticles being deposited throughout the body. Although relatively inert and non-toxic in low concentrations, the long term effects are still unknown. For this reason, this study focuses on enhancing AuNP laser thermal therapy through ultrasound-microbubble enhanced cell permeability with the intent of decreasing the gold concentration required for treatment. 


\subsection{Ultrasound and Microbubbles}

A microbubble is a small gas bubble with a diameter of 1 to 10 micrometers (Ferrara et al., 2007). Microbubbles respond to pressure waves due to their high compressibility. The gas compresses under high pressure and expands under low pressure. Naturally, when exposed to an ultrasonic pulse, a microbubble will expand and contract along with the pressure oscillations. The oscillations are dependent on the frequency and pressure of the ultrasound wave along with microbubble size, shell thickness, composition, and surrounding media density (Ferrara et al., 2007). The contraction and expansion of the microbubble generates a force on the surrounding fluid leading to micro-streaming that can disturb its surroundings. When microbubbles are injected into the body, their behavior can induce biological effects including enhanced cell permeability and drug delivery.

\subsubsection{Ultrasound and microbubble physics}

Microbubbles were initially used as contrast agents for ultrasound imaging of the vascular system. Due to the large density difference between blood and gas, microbubbles in the vasculature generate a higher acoustic backscatter compared to surrounding tissues causing them to appear bright in a Contrast Enhanced Ultrasound (CEUS) image. Clinically, microbubbles are considered minimally invasive and are injected into the vasculature to detect perfusion and blood flow in echocardiography along with other organs of interest. Microbubbles exposed to high acoustic pressure generate unique backscatter signals with nonlinear harmonics, not present in 
normal tissue, enhancing the signal to noise ratio by allowing their signal to be isolated from an image.

Microbubble behavior in response to ultrasound waves has been categorized as either linear cavitation, non-linear cavitation, or inertial cavitation. Linear cavitation occurs when there is an equal expansion and contraction about the bubble's equilibrium radius. At higher exposure pressures microbubbles undergo non-linear cavitation where there is an unequal expansion and contraction. Inertial cavitation is a violent collapse of the bubble due to the inertia of the fluid displaced by the microbubble during its expansion phase. In general, inertial cavitation occurs when the microbubble expands past twice its equilibrium radius and the inertia of the surrounding fluid causes it to implode rapidly. Linear and non-linear cavitation cause microstreaming around the bubbles and inertial cavitation causes bubble collapse or fragmentation generating shock waves, sonoluminescence, extreme heat, and can produce free radicals (Unger et al., 2001).

\subsubsection{Ultrasound-microbubbles for targeting drug delivery}

First generation microbubbles were made from air and had a very short lifetime in the blood due to their quick diffusion and efficiency of the lungs to filter them out. Currently, second generation microbubbles are being used for CEUS which are filled with a heavy inert gas and have a stabilizing shell made of lipid, albumin or polymer to increase their circulation lifetime. As an added benefit, the coating allows for the addition of targeting ligands or antibodies which allow microbubbles to attach to an area of interest in the body. Currently, 
clinically approved microbubbles contain perfluorocarbon gas and include Definity, which has a lipid shell, and Optison, which has an albumin shell.

In response to ultrasound waves, microbubbles generate shear stress on surrounding targets such as cell membranes. The shear stress can cause pore formation and provide a transient passageway for drugs to enter cells (Figure 1.2). Large pore formation can also be severe enough to cause cell death. The likelihood of membrane disruptions being reversible is dependent on the acoustic exposure conditions. In general, increased cell permeability is correlated with increased cell death (Karshafian et al., 2009). Increasing acoustic pressure, duty cycle, insonation time and decreasing ultrasound frequency have been found to increase cell permeability and decrease cell viability (Karshafian et al., 2009). 


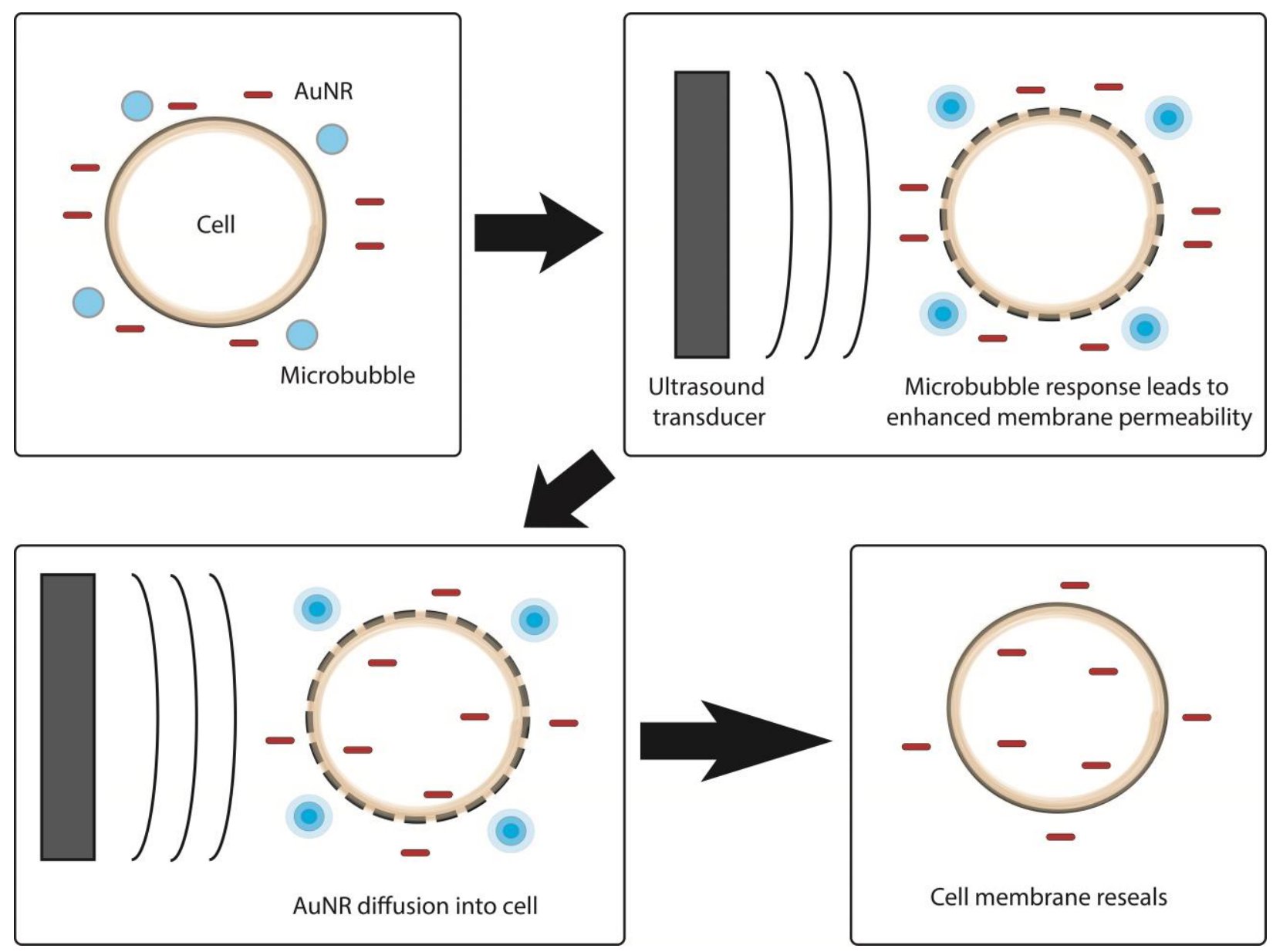

Figure 1.2. Process of sonoporation. Microbubbles stimulated by ultrasound waves oscillate resulting in enhanced cell membrane permeability. Drugs can temporarily diffuse across the cell membrane. When the cell membrane reseals the drugs become trapped inside the cell. 


\subsubsection{Ultrasound-microbubble bio-effects in vivo}

Ultrasound can be focused to a region the size of few millimeters which creates a localized enhanced permeability effect. In vivo, microbubbles are injected into the vasculature and interact mainly with the small vessel and capillary structures (Figure 1.3). Ultrasound causes the microbubbles to damage the microvasculature allowing for enhanced permeability and leakage of inter-vascular contents into the interstitial tissues. Early studies by Skyba et al. (Skyba et al., 1998) on muscle microvasculature in mice have shown capillary rupture and cell damage that correlate with the acoustic energy delivered. Their results show localized damage to and around microvasculature $\leq 7 \mu \mathrm{m}$ in diameter (Skyba et al., 1998). Micro-vessel ruptures due to ultrasound and microbubbles can be large enough to allow for red blood cell extravasation limited to the rupture site (Price et al., 1998). Stieger et al. (Stieger et al., 2007) showed increased extravasation of material through micron sized openings due to increased ultrasonic pressure and decreased central frequency.

The USMB effect is not limited to capillaries. Hwang et al. (Hwang et al., 2005) studied the effect on vessels approximately $1 \mathrm{~mm}$ in diameter. Their results showed greater endothelial cell damage along the distal side (further from the ultrasound transducer) of acoustically exposed vessels proportional to acoustic pressure. In contrast, the proximal side of the vessel (closer to the transducer) showed minimal damage to the vessel. A likely explanation for the asymmetry in results is due to acoustic radiation force pushing microbubbles away from the transducer towards the vessel wall. In addition, Hwang et al. (Hwang et al., 2005) observed platelet adhesion on the damaged side of the vessel which is a key step in coagulation. As a response to the trauma caused by ultrasound and microbubbles, vasoconstriction can occur in the exposed area which 
can lead to a localized reduction in blood flow (Hirokawa et al., 2007; Raymond et al., 2007;

Vykhodtseva et al., 2007).

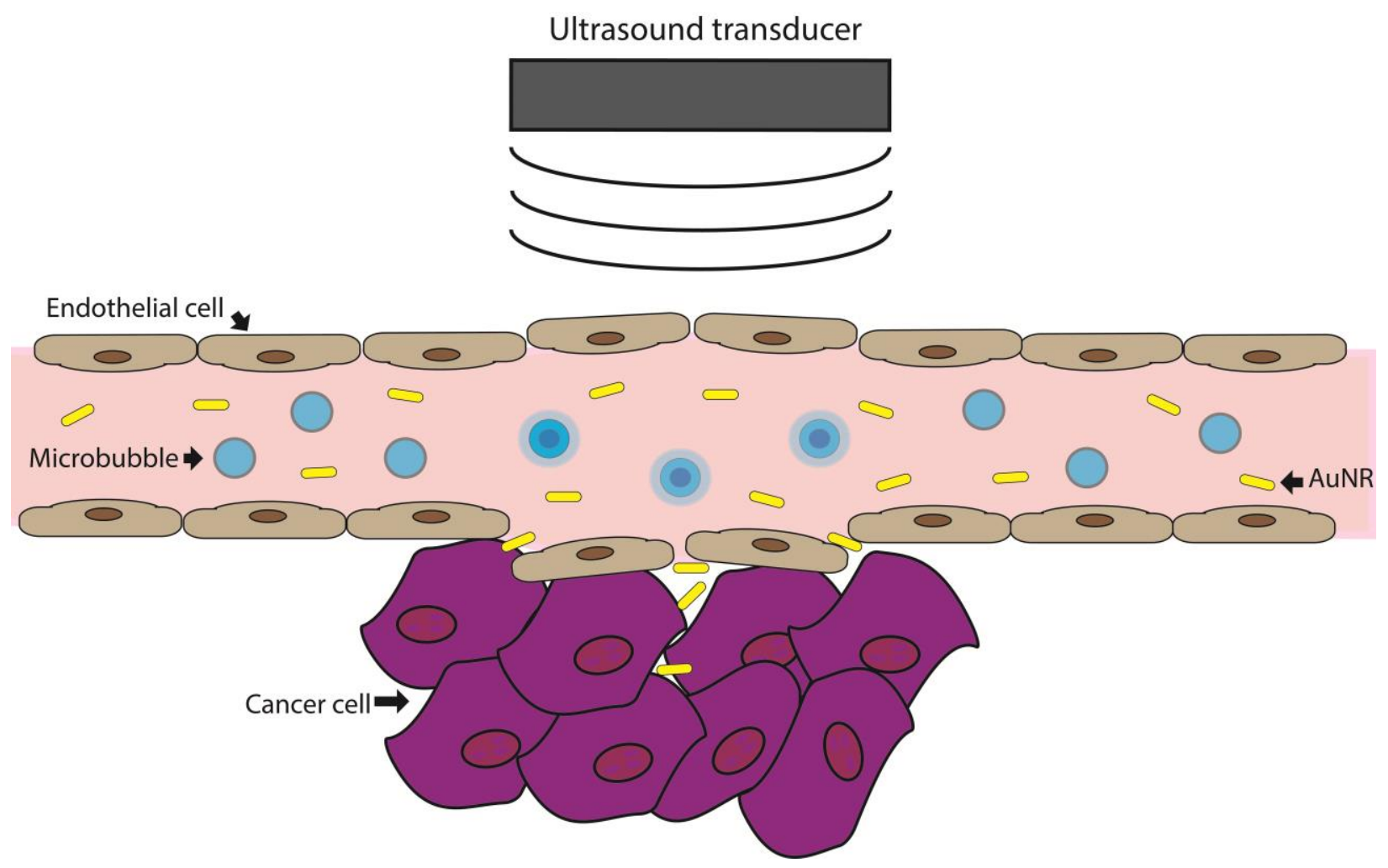

Figure 1.3. Ultrasound and microbubble effects on microvasculature. Within the acoustic field microbubbles oscillate and disrupt the surrounding endothelial cells. This allows for drugs such as gold nanorods (AuNR) to leak out of the vessel towards the surrounding cancerous cells. 


\subsection{Hypothesis and specific objectives}

This study addresses the hypothesis that gold nanorod laser thermal therapy combined with ultrasound and microbubbles enhances cell death in vitro compared to either treatment on its own. In this study, a suspension of MDA-MB-231 breast cancer cells was exposed to PEGylated gold nanorods and combinations of ultrasound-microbubble and laser therapy. Throughout laser irradiation, bulk sample temperature was monitored using a thermal camera.

The specific objectives are:

- To determine whether the combined effect of ultrasound-microbubbles and PEG coated gold nanorod laser thermal therapy decreases cell viability compared to either treatment on its own in an in vitro breast cancer cell model (MDA-MB231).

- To determine the effect of treatment order on cell viability and whether there is a synergistic, additive or protective effect.

- To measure sample temperature to determine whether treatment order has an effect on bulk temperature. 


\subsection{References}

Anderson, R.R., Parrish, J.A., 1981. The Optics of Human Skin. J Investig Dermatol 77, 13-19.

Boisselier, E., Astruc, D., 2009. Gold nanoparticles in nanomedicine: preparations, imaging, diagnostics, therapies and toxicity. Chem. Soc. Rev. 38, 1759-1782.

Chang, S.-S., Shih, C.-W., Chen, C.-D., Lai, W.-C., Wang, C.R.C., 1999. The Shape Transition of Gold Nanorods. Langmuir 15, 701-709.

Chen, C.-L., Kuo, L.-R., Chang, C.-L., Hwu, Y.-K., Huang, C.-K., Lee, S.-Y., Chen, K., Lin, S.J., Huang, J.-D., Chen, Y.-Y., 2010. In situ real-time investigation of cancer cell photothermolysis mediated by excited gold nanorod surface plasmons. Biomaterials 31, 4104-4112.

Chithrani, B.D., Chan, W.C., 2007. Elucidating the mechanism of cellular uptake and removal of protein-coated gold nanoparticles of different sizes and shapes. Nano Lett. 7, 1542-1550.

Choi, C.H.J., Alabi, C.A., Webster, P., Davis, M.E., 2010. Mechanism of active targeting in solid tumors with transferrin-containing gold nanoparticles. Proc. Natl. Acad. Sci. 107, 12351240.

Coakley, W.T., 1986. Hyperthermia effects on the cytoskeleton and on cell morphology., in: Symposia of the Society for Experimental Biology. pp. 187-211.

Connor, E.E., Mwamuka, J., Gole, A., Murphy, C.J., Wyatt, M.D., 2005. Gold nanoparticles are taken up by human cells but do not cause acute cytotoxicity. Small 1, 325-327.

Diederich, C.J., 2005. Thermal ablation and high-temperature thermal therapy: overview of technology and clinical implementation. Int. J. Hyperthermia 21, 745-753.

Dobrovolskaia, M.A., McNeil, S.E., 2007. Immunological properties of engineered nanomaterials. Nat. Nanotechnol. 2, 469-478.

Ferrara, K., Pollard, R., Borden, M., 2007. Ultrasound microbubble contrast agents: Fundamentals and application to gene and drug delivery.

Gad, S.C., Sharp, K.L., Montgomery, C., Payne, J.D., Goodrich, G.P., 2012. Evaluation of the Toxicity of Intravenous Delivery of Auroshell Particles (Gold-Silica Nanoshells). Int. J. Toxicol. 31, 584-594.

Hildebrandt, B., Wust, P., Ahlers, O., Dieing, A., Sreenivasa, G., Kerner, T., Felix, R., Riess, H., 2002. The cellular and molecular basis of hyperthermia. Crit. Rev. Oncol. Hematol. 43, 33-56.

Hirokawa, T., Karshafian, R., Pavlin, C.J., Burns, P.N., 2007. Insonation of the Eye in the Presence of Microbubbles Preliminary Study of the Duration and Degree of Vascular Bioeffects - Work in Progress. J. Ultrasound Med. 26, 731-738.

Huang, X., El-Sayed, I.H., Qian, W., El-Sayed, M.A., 2006. Cancer cell imaging and photothermal therapy in the near-infrared region by using gold nanorods. J. Am. Chem. Soc. 128, 2115-2120.

Hwang, J.H., Brayman, A.A., Reidy, M.A., Matula, T.J., Kimmey, M.B., Crum, L.A., 2005. Vascular effects induced by combined 1-MHz ultrasound and microbubble contrast agent treatments in vivo. Ultrasound Med. Biol. 31, 553-564.

Jain, P.K., Lee, K.S., El-Sayed, I.H., El-Sayed, M.A., 2006. Calculated absorption and scattering properties of gold nanoparticles of different size, shape, and composition: Applications in biological imaging and biomedicine. J. Phys. Chem. B 110, 7238-7248.

Karshafian, R., Bevan, P.D., Williams, R., Samac, S., Burns, P.N., 2009. Sonoporation by Ultrasound-Activated Microbubble Contrast Agents: Effect of Acoustic Exposure 
Parameters on Cell Membrane Permeability and Cell Viability. Ultrasound Med. Biol. 35, $847-860$.

Kelly, K.L., Coronado, E., Zhao, L.L., Schatz, G.C., 2003. The optical properties of metal nanoparticles: The influence of size, shape, and dielectric environment. J. Phys. Chem. B 107, 668-677.

Kittel, C., McEuen, P., 1986. Introduction to solid state physics. Wiley New York.

Lagendijk, J.J.W., 2000. Hyperthermia treatment planning. Phys. Med. Biol. 45, R61-R76.

Link, S., El-Sayed, M.A., 2005. Simulation of the optical absorption spectra of gold nanorods as a function of their aspect ratio and the effect of the medium dielectric constant. J. Phys. Chem. B 109, 10531-10532.

Link, S., Burda, C., Wang, Z.L., El-Sayed, M.A., 1999. Electron dynamics in gold and goldsilver alloy nanoparticles: The influence of a nonequilibrium electron distribution and the size dependence of the electron-phonon relaxation. J. Chem. Phys. 111, 1255-1264.

Lipka, J., Semmler-Behnke, M., Sperling, R.A., Wenk, A., Takenaka, S., Schleh, C., Kissel, T., Parak, W.J., Kreyling, W.G., 2010. Biodistribution of PEG-modified gold nanoparticles following intratracheal instillation and intravenous injection. Biomaterials 31, 65746581.

Longmire, M., Choyke, P.L., Kobayashi, H., 2008. Clearance properties of nano-sized particles and molecules as imaging agents: considerations and caveats.

Lukianova-Hleb, E.Y., Belyanin, A., Kashinath, S., Wu, X., Lapotko, D.O., 2012. Plasmonic nanobubble-enhanced endosomal escape processes for selective and guided intracellular delivery of chemotherapy to drug-resistant cancer cells. Biomaterials 33, 1821-1826.

Malugin, A., Ghandehari, H., 2010. Cellular uptake and toxicity of gold nanoparticles in prostate cancer cells: a comparative study of rods and spheres. J. Appl. Toxicol. 30, 212-217.

Murphy, C.J., Gole, A.M., Stone, J.W., Sisco, P.N., Alkilany, A.M., Goldsmith, E.C., Baxter, S.C., 2008. Gold nanoparticles in biology: beyond toxicity to cellular imaging. Acc. Chem. Res. 41, 1721-1730.

Nanospectra Biosciences, Inc., 2013. Pilot Study of AuroLase(tm) Therapy in Refractory and/or Recurrent Tumors of the Head and Neck. NCT00848042.

Niidome, T., Yamagata, M., Okamoto, Y., Akiyama, Y., Takahashi, H., Kawano, T., Katayama, Y., Niidome, Y., 2006. PEG-modified gold nanorods with a stealth character for in vivo applications. J. Controlled Release 114, 343-347.

Nylandsted, J., Brand, K., Jäättelä, M., 2000. Heat shock protein 70 is required for the survival of cancer cells. Ann. N. Y. Acad. Sci. 926, 122-125.

O’Neal, D.P., Hirsch, L.R., Halas, N.J., Payne, J.D., West, J.L., 2004. Photo-thermal tumor ablation in mice using near infrared-absorbing nanoparticles. Cancer Lett. 209, 171-176.

Oberdörster, G., Stone, V., Donaldson, K., 2007. Toxicology of nanoparticles: a historical perspective. Nanotoxicology 1, 2-25.

Price, R.J., Skyba, D.M., Kaul, S., Skalak, T.C., 1998. Delivery of colloidal particles and red blood cells to tissue through microvessel ruptures created by targeted microbubble destruction with ultrasound. Circulation 98, 1264-1267.

Qin, Z., Bischof, J.C., 2012. Thermophysical and biological responses of gold nanoparticle laser heating. Chem. Soc. Rev. 41, 1191-1217.

Raymond, S.B., Skoch, J., Hynynen, K., Bacskai, B.J., 2007. Multiphoton imaging of ultrasound/Optison mediated cerebrovascular effects in vivo. J. Cereb. Blood Flow Metab. 27, 393-403. 
Rylander, M.N., Feng, Y., Bass, J., Diller, K.R., 2005. Thermally induced injury and heat-shock protein expression in cells and tissues. Ann. N. Y. Acad. Sci. 1066, 222.

Sapareto, S.A., Dewey, W.C., 1984. Thermal dose determination in cancer therapy. Int. J. Radiat. Oncol. Biol. Phys. 10, 787-800.

Siegal, R.J., Vaezy, S., Martin, R., Crum, L., 2001. Therapeutic Ultrasound, Part II*. Echocardiography 18, 309-315.

Skyba, D.M., Price, R.J., Linka, A.Z., Skalak, T.C., Kaul, S., 1998. Direct in vivo visualization of intravascular destruction of microbubbles by ultrasound and its local effects on tissue. Circulation 98, 290-293.

Smith, A.M., Mancini, M.C., Nie, S., 2009. Second window for in vivo imaging. Nat. Nanotechnol. 4, 710.

Sokolov, K., Tam, J., Tam, J., Travis, K., Larson, T., Aaron, J., Harrison, N., Emelianov, S., Johnston, K., 2009. Cancer imaging and therapy with metal nanoparticles. Conf. Proc. Annu. Int. Conf. IEEE Eng. Med. Biol. Soc. IEEE Eng. Med. Biol. Soc. Conf. 2009, 2005-2007.

Stieger, S.M., Caskey, C.F., Adamson, R.H., Qin, S., Curry, F.-R.E., Wisner, E.R., Ferrara, K.W., 2007. Enhancement of Vascular Permeability with Low-Frequency Contrastenhanced Ultrasound in the Chorioallantoic Membrane Model 1. Radiology 243, 112 121.

Storm, F.K., Harrison, W.H., Elliott, R.S., Morton, D.L., 1979. Normal tissue and solid tumor effects of hyperthermia in animal models and clinical trials. Cancer Res. 39, 2245-2251.

Unger, E.C., Hersh, E., Vannan, M., Matsunaga, T.O., McCreery, T., 2001. Local drug and gene delivery through microbubbles. Prog. Cardiovasc. Dis. 44, 45-54.

Vykhodtseva, N., McDannold, N., Hynynen, K., 2007. Effects of high intensity focused ultrasound on the brain. Presented at the 6th International Symposium on Therapeutic Ultrasound, AIP Publishing, pp. 535-541.

Wang, C.Y., Maibach, H.I., 2013. Immunologic contact urticaria-the human touch. Cutan. Ocul. Toxicol. 32, 154-160.

West, J.L., Halas, N.J., 2003. Engineered nanomaterials for biophotonics applications: Improving sensing, imaging, and therapeutics. Annu. Rev. Biomed. Eng. 5, 285-292.

Young, A.R., 1997. Chromophores in human skin. Phys. Med. Biol. 42, 789.

Yu, Y.-Y., Chang, S.-S., Lee, C.-L., Wang, C.C., 1997. Gold nanorods: electrochemical synthesis and optical properties. J. Phys. Chem. B 101, 6661-6664.

Zhang, X.-D., Wu, D., Shen, X., Liu, P.-X., Yang, N., Zhao, B., Zhang, H., Sun, Y.-M., Zhang, L.-A., Fan, F.-Y., 2011. Size-dependent in vivo toxicity of PEG-coated gold nanoparticles. Int. J. Nanomedicine 6, 2071. 


\title{
2. Enhancing laser thermal therapy using PEGylated gold nanoparticles combined with ultrasound and microbubbles
}

\author{
C. Tarapacki and R. Karshafian
}

\begin{abstract}
Background: Gold nanorod laser thermal therapy $(\mathrm{AuNR}+\mathrm{L})$ is a non-invasive method of increasing the temperature of a target tissue using near infrared light. In this study, the effects of ultrasound and microbubbles (USMB) with AuNR and laser therapy were investigated on cell viability.
\end{abstract}

Methods: MDA-MB-231 cells in suspension were treated with combinations of (1) USMB at $500 \mathrm{kHz}$ frequency, 16 cycles, $1 \mathrm{kHz}$ pulse repetition frequency and peak negative pressure of 0.6 or $1.0 \mathrm{MPa}$ for one minute in the presence of Definity microbubbles $(1.7 \% \mathrm{v} / \mathrm{v}),(2) \mathrm{mPEG}$ coated AuNR with a peak absorption wavelength at $813 \mathrm{~nm}$ at a sample concentration of $3 \times 10^{11}$ $\mathrm{np} / \mathrm{mL}$ and (3) laser (L) at $810 \mathrm{~nm}$ and $1.9 \mathrm{~W} / \mathrm{cm}^{2}$ for three minutes. Cells were treated with three different treatment orders of AuNR, laser and USMB: 1) AuNR+USMB followed by L, 2) AuNR + L followed by USMB, and 3) USMB followed by AuNR+L. Following the treatment, cell viability was assessed using propidium iodide fluorescent marker and flow cytometry $\left(\mathrm{V}_{\mathrm{PI}}\right)$, and colony assay $\left(\mathrm{V}_{\mathrm{CA}}\right)$. Sample temperature was monitored with a thermal camera during laser treatment. Cell viabilities were compared using student t-test and synergism was assessed using the Bliss Independence Model. 
Results and discussion: USMB improved cell death when combined with AuNR+L. $\mathrm{V}_{\mathrm{PI}}$ of $17 \pm 2 \%$ (at $0.6 \mathrm{MPa}$ ) and $11 \pm 4 \%$ (at $1.0 \mathrm{MPa}$ ) were observed with combined treatment of AuNR and USMB followed by $\mathrm{L}$ compared to $\mathrm{V}_{\mathrm{PI}}$ of $22 \pm 3 \%$ with AuNR $+\mathrm{L}, \mathrm{V}_{\mathrm{PI}}$ of $60 \pm 2 \%$ with USMB at $0.6 \mathrm{MPa}$, and $42 \pm 3 \%$ with USMB at $1.0 \mathrm{MPa}$ alone. The effect of AuNR+L and USMB combined treatment was additive regardless of treatment order. Combining AuNR $+\mathrm{L}$ and USMB resulted in predicted additive viabilities of $13 \pm 2 \%$ for $0.6 \mathrm{MPa}$ and $9 \pm 2 \%$ for $1.0 \mathrm{MPa}$ peak negative pressures. Cell viability varied minimally with treatment order. The most significant therapeutic effect occurred when AuNR+L was performed prior to USMB at $1.0 \mathrm{MPa}$ which decreased $\mathrm{V}_{\mathrm{PI}}$ to $7 \pm 1 \%$. $\mathrm{V}_{\mathrm{CA}}$ results agreed with the additive effect caused by combining AuNR+L and USMB for all treatment orders. In the absence of AuNR, samples exposed to laser prior to ultrasound treatment at $0.6 \mathrm{MPa}$ increased $\mathrm{V}_{\mathrm{PI}}$ by $13 \%(\mathrm{p}<0.01)$ showing a protective effect.

Conclusion: Combining AuNR+L and USMB resulted in an additive effect on cell viability compared to AuNR+L and USMB on their own. In addition, cells exposed to low intensity NIR light appear to be protected against ultrasound and microbubble exposure. 


\subsection{Introduction}

Gold nanorod laser thermal therapy $(\mathrm{AuNR}+\mathrm{L})$ can increase the local temperature in target areas such as solid tumors (Chen et al., 2010; Grossman and McNeil, 2012; Hauck et al., 2008; Lal et al., 2008; Sokolov et al., 2009). Gold nanoparticles exhibit surface plasmon resonance (SPR) when exposed to light and transfer the energy to their surroundings. The SPR absorption peak wavelength depends on the gold nanoparticle shape and size. Gold nanorods (AuNR) with an aspect ratio (length/width) of 4 have an SPR peak near $800 \mathrm{~nm}$ which is within the optical window of the body (600 to $1300 \mathrm{~nm}$ ) and allows for minimum energy absorption by body tissues (Anderson and Parrish, 1981; Chang et al., 1999). AuNR have absorption cross sections approximately 4 orders of magnitude higher than other absorption agents such as Indocyanine Green (ICG), causing fewer nanoparticles to be required to induce thermal effects (Jain et al., 2006). Gad et al. (Gad et al., 2012) performed gold nanoparticle toxicity studies on mice, rats, and beagle dogs demonstrating that $150 \mathrm{~nm}$ gold nanospheres were retained within the body throughout the 300 days of the study. The gold nanoparticles were filtered out of the bloodstream; however, they remained inside the organs of the reticuloendothelial system (liver and spleen). Although the presence of the gold did not appear to affect the animals' health within the one year study, decreasing the nanoparticle concentration will decrease the potential longer term risks associated with the treatment. In addition, increased nanoparticle localization and concentration within the tumors has potential to improve the effectiveness of thermal treatment and reduce normal tissue toxicity.

The application of ultrasound and microbubbles (USMB) has been shown to enhance effectiveness of chemotherapy (Duvshani-Eshet et al., 2007; Goertz et al., 2012; Todorova et al., 2013) and radiotherapy (Czarnota et al., 2012; Nofiele et al., 2013) in both in vitro and in vivo 
tumor models. USMB induces reversible and irreversible increase in cell membrane permeability through a process known as sonoporation (Hu et al., 2013; Karshafian et al., 2010, 2009). The stress can induce a variety of biological pathways that lead to increased endocytosis (Meijering et al., 2009) or increased ceramide production leading to apoptotic pathways (Al-Mahrouki et al., 2012). The acoustic mechanism has been associated with biomechanical perturbation of biological membranes induced by microbubbles undergoing non-linear oscillation and inertial cavitation, and generating shear stress on biological membranes in its vicinity (Doinikov and Bouakaz, 2010; Qiu et al., 2010; Wu et al., 2002). Membrane disruptions of 30-150 nm range with up to $5 \mu \mathrm{m}$ were observed in cells allowing intracellular uptake of nanoparticles and small molecules (Zhao et al., 2008; Zhou et al., 2009). The resealing of the membrane disruptions depends on the size of the pore and generally reseals within one minute (Hu et al., 2013). Small pores $\left(<30 \mu \mathrm{m}^{2}\right)$ were able to shrink or reseal successfully.

Our previous study demonstrated a significant increase in cell death of Acute Myeloid Leukemia cells (AML) following exposure to NIR light and gold nanorods in combination with USMB compared to 12 hour incubation with gold nanoparticles (Tarapacki et al., 2013) . The previous experiments were conducted using cetyltrimethylammonium bromide (CTAB) to coat the gold nanorods which helps stabilize the particles, however, it is toxic to cells (Lau et al., 2012; Wang et al., 2013, 2008). Clinically approved nanoparticles require a lower toxicity and are often stabilized with a polyethylene glycol (PEG) coating which increases the particle's biocompatibility and circulation time in the blood (Lipka et al., 2010; Simpson et al., 2011). This study aims to determine the bioeffects of ultrasound and microbubbles in combination with PEG-coated gold nanoparticle laser thermal therapy on breast cancer cells, and assess the effect of the treatment order. 


\subsection{Methods}

\subsubsection{In vitro cell model}

An epithelial breast cancer cell line, MDA-MB-231, was cultured in RPMI1640 culture media supplemented with $10 \%$ fetal bovine serum (FBS). Cells were grown in a $37^{\circ} \mathrm{C}$ hermetically closed incubator with $5 \% \mathrm{CO}_{2}$. They were removed from culture flasks through trypsinization and counted to a sample concentration of $1.5 \times 10^{6}$ cells $/ \mathrm{mL}$. Cells were exposed to ultrasound and microbubbles (USMB), gold nanorods (AuNR) and laser (L) and their combination with and without centrifuging the samples to remove the AuNR from the suspension prior to laser treatment. Centrifuged samples were washed twice with $10 \mathrm{~mL}$ PBS through centrifugation at $115 \mathrm{rcf}$ for two minutes and re-suspended in $0.6 \mathrm{~mL}$ media prior to laser treatment to remove AuNR from suspension. In all conditions, cells were exposed to laser within 15 minutes following the addition of AuNR to the cell suspension. Figure 2.1 shows a timeline for the combined treatments tested. 


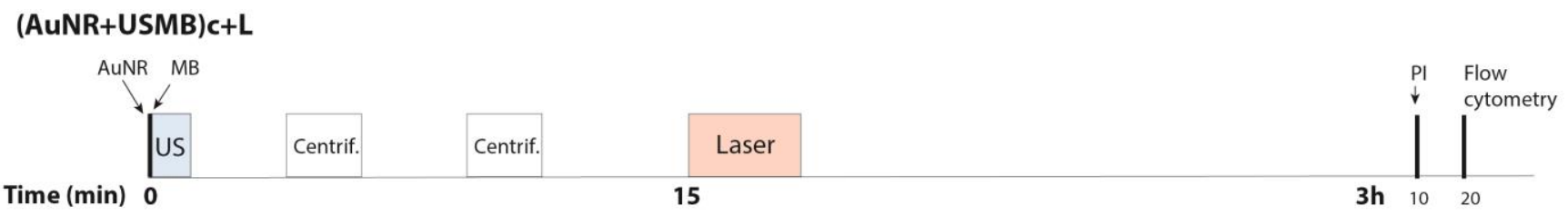

(AuNR+USMB)+L

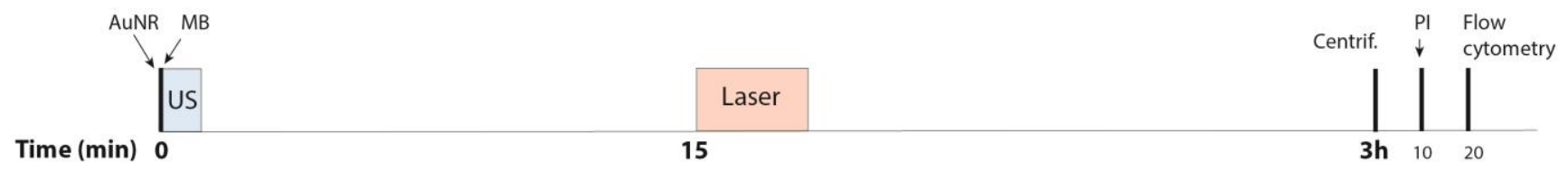

(AUNR+L)+USMB

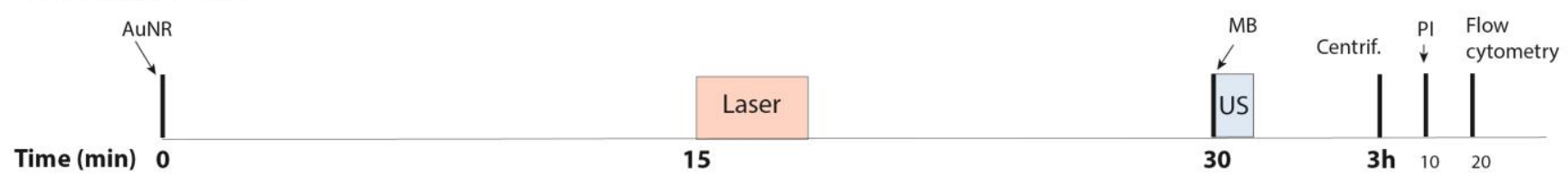

USMB+(AuNR+L)

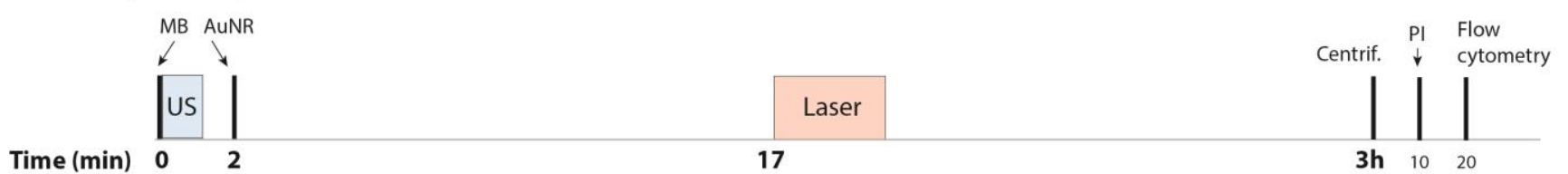

Figure 2.1 Treatment timeline for the varying treatment combinations of gold nanorod thermal therapy with ultrasound and microbubbles. The time of gold nanorod (AuNR), microbubble (MB) and propidium iodide (PI) addition, ultrasound (US), and laser treatment, centrifuging, and flow cytometry measurements.

\subsubsection{Gold nanoparticles}

Gold nanorods of 10x41 nm size (aspect ratio of 4.1), conjugated with 5K methylpolyethylene glycol (mPEG) and suspended in phosphate buffered saline (PBS) at a concentration of $5.5 \times 10^{13} \mathrm{nps} / \mathrm{mL}$ was purchased (AR12-10-808-5KMPEG-50, Nanopartz ${ }^{\mathrm{TM}}$, Loveland, CO, USA). Cells were treated with AuNR at a concentration of $3.0 \times 10^{11} \mathrm{nps} / \mathrm{mL}$. The surface plasmon resonance peak of the AuNR was $813 \mathrm{~nm}$. 


\subsubsection{Ultrasound-microbubble treatment}

A schematic diagram of the ultrasound apparatus is shown in Figure 2.2. Cells were exposed to ultrasound at $500 \mathrm{kHz}$ center frequency and peak negative pressures $\left(\mathrm{P}_{\text {neg }}\right)$ of 0.6 and $1.0 \mathrm{MPa}$. The ultrasound treatment was delivered using a single element focused transducer (IL0508HP, Valpey Fisher Inc, Hopkinton, MA) with a $-6 \mathrm{~dB}$ beam width of $9.2 \mathrm{~mm}$ and $50 \mathrm{~mm}$ focal length. The ultrasound treatment sequence consisted of $32 \mu$ s tone-burst pulse at $1 \mathrm{kHz}$ pulse repetition frequency (3.2\% duty cycle) for a total treatment of 60 seconds. Immediately prior to ultrasound treatment, a volume of $10 \mu \mathrm{L}(1.7 \% \mathrm{vol} / \mathrm{vol})$ Definity ${ }^{\circledR}$ microbubbles (Lantheus Medical Imaging Inc., Saint-Laurent, QC, CA) was added to each cell suspension $(0.6 \mathrm{~mL})$. The microbubbles comprised of Perflutren lipid-coated microspheres filled with octafluoropropane gas and were activated using a Vialmix for 45 seconds.

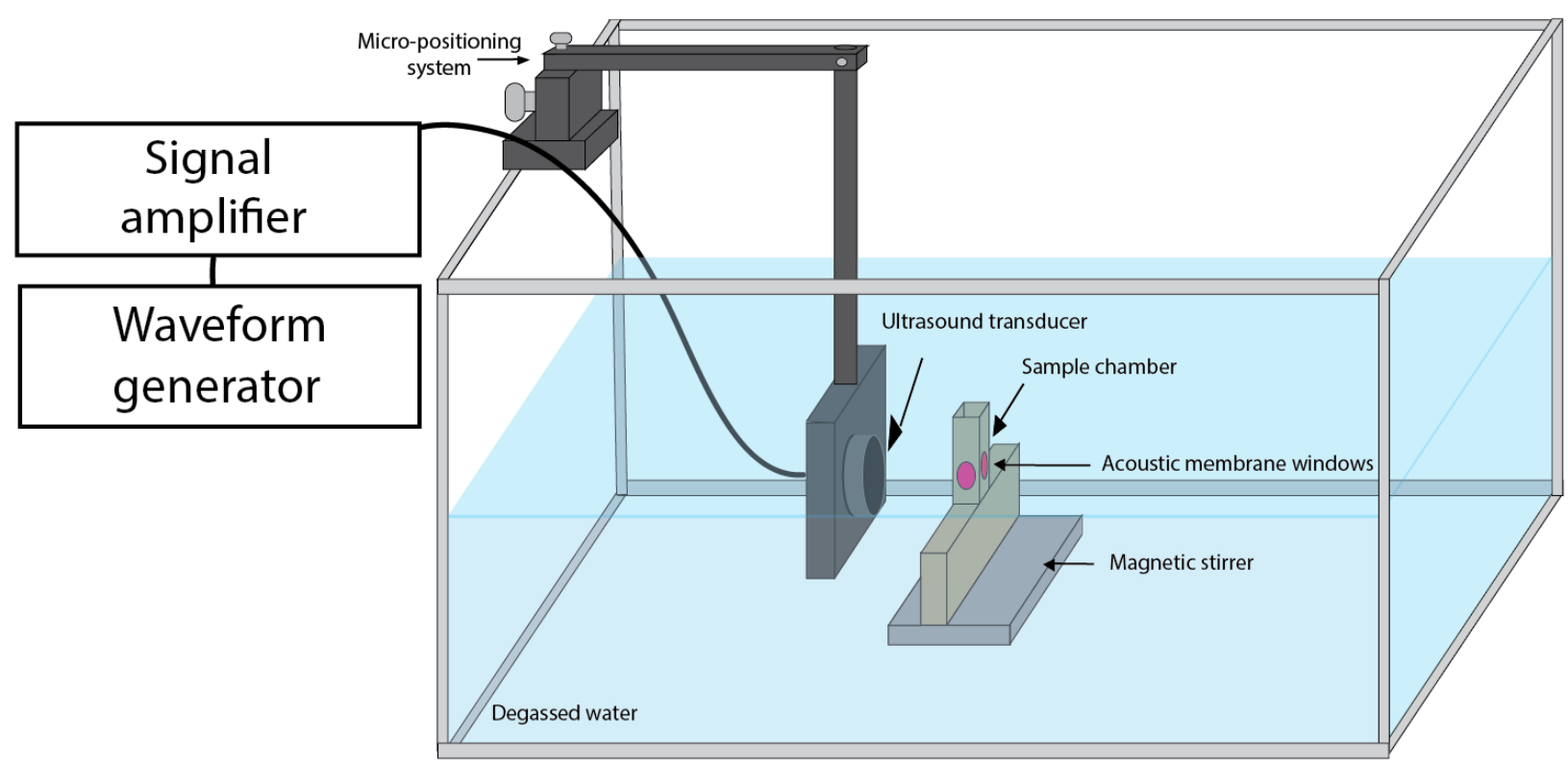

Figure 2.2 Ultrasound treatment setup. A signal is generated on a waveform generator, amplified and sent to the ultrasound transducer which is connected to and controlled by a micro-positioning system. The sample chamber has 4 acoustic windows and rests on a magnetic stirrer. Cell suspensions are placed inside and covered with Parafilm. 


\subsubsection{Thermal treatment and monitoring}

A schematic diagram of the laser therapy setup is shown in Figure 2.3. Cell samples of 0.6 $\mathrm{mL}$, suspended in RPMI1640 media with 10\% FBS, were treated with NIR light with an $810 \mathrm{~nm}$, continuous wave Diomed-60 laser (Diomed Ltd., Cambridge, UK) at $4 \mathrm{~W}$ for $3 \mathrm{~min}$. A 0.37 NA flat tip laser fiber, core diameter of $1000 \mu \mathrm{m}( \pm 2 \%$, BFL37-1000, Thorlabs, Newton, NJ, USA ), was positioned $19 \mathrm{~mm}$ away from the bottom of a single well of a 24-well flat bottom plate (83.1836, Starstedt Inc, Montreal, QC, CA $)$ inside a $37^{\circ} \mathrm{C}\left( \pm 2^{\circ} \mathrm{C}\right)$ incubator. The laser intensity at the bottom of the well during treatment was $1.9 \mathrm{~W} / \mathrm{cm}^{2}$. Throughout the laser treatment, a FLIR Thermovision A40 thermal camera (Burlington, ON, CA) was focused on the sample to monitor the temperature. The average temperature of the sample prior to laser treatment was $\sim 35^{\circ} \mathrm{C}$. The average temperature in the center of the sample was calculated using ThermaCAM Researcher 2.10 Pro (FLIR Systems Inc.). The thermal dose was calculated in terms of the cumulative equivalent minutes at $43^{\circ} \mathrm{C}$ (CEM43) using a time step of 5 seconds:

$$
C E M 43=\sum_{i=1}^{N} R_{C E M}{ }^{\left(43-T_{i}\right)} t_{i}
$$

where $R_{\text {CEM }}$ is the constant of proportionality for the process -0.5 for temperatures above $43^{\circ} \mathrm{C}$ and 0.25 for temperatures below $43^{\circ} \mathrm{C} . \mathrm{T}_{\mathrm{i}}$ is the temperature of the time interval " $\mathrm{i}$ " in Celsius and $t_{i}$ is the time at $T_{i}$ in minutes. 


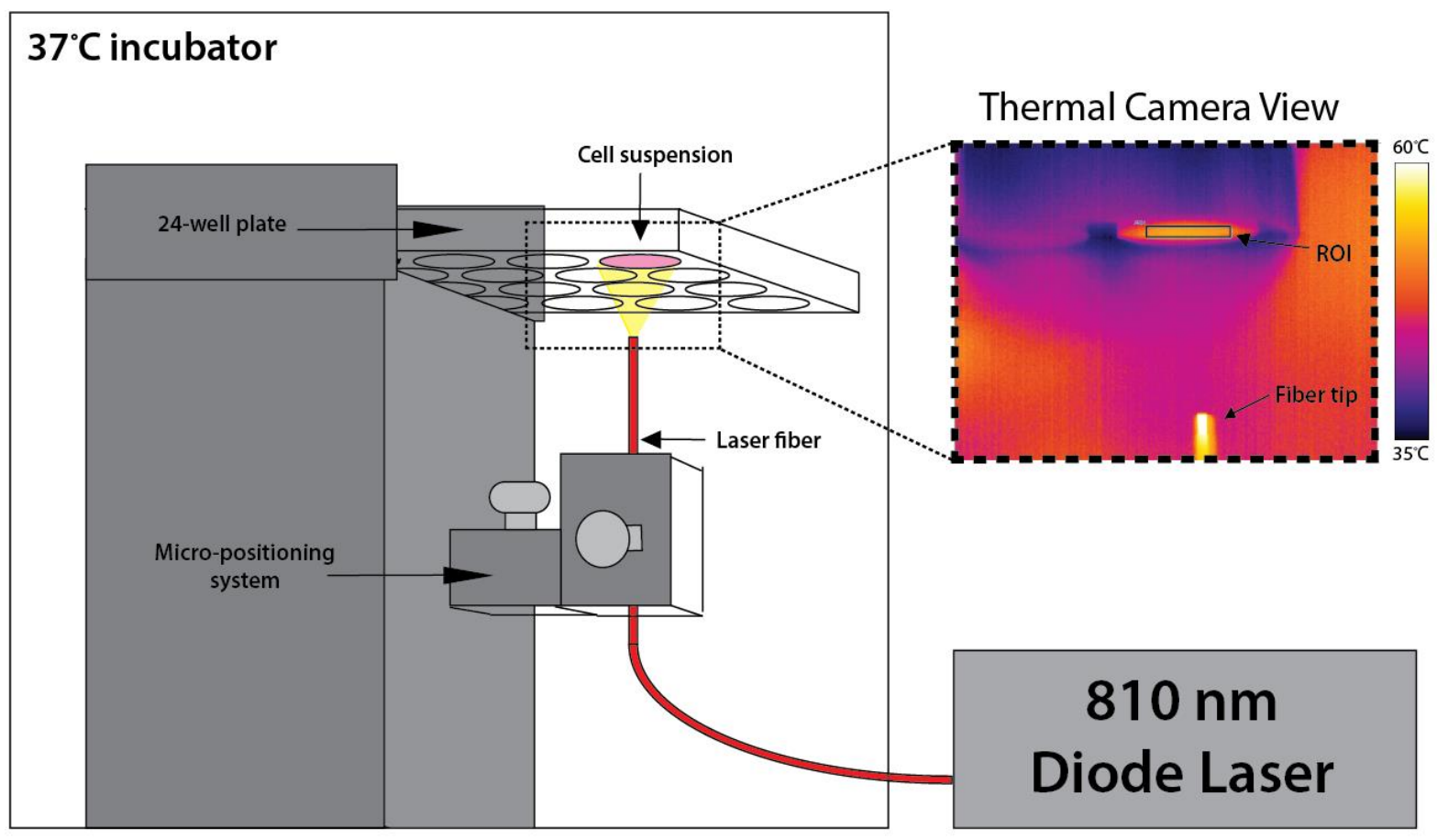

Figure 2.3 Laser therapy setup. Cell suspensions were placed in a corner well of a 24-well plate and positioned above a laser fiber connected to an $810 \mathrm{~nm}$ continuous wave (CW) diode laser. A thermal camera was positioned perpendicular to the laser fiber with a view shown in the insert on the top right corner. The region of interest (ROI) selected was on the bottom of the well and shown in the insert.

\subsubsection{Viability analysis}

Cell viability was assessed using propidium iodide (PI, P3566, Invitrogen, Carlsbad, CA, USA) fluorescent molecule with flow cytometry (BD FACSCalibur, BD Biosciences, Mississauga, ON, CA) and clonogenic assay. PI fluoresces when bound to nucleic acids, causing flow cytometry to label PI positive cells as dead and PI negative cells as alive (Sasaki et al., 1987). Cell viability using PI was assessed three hours after the treatment. Following centrifugation to remove excess nanoparticles from solution, a volume of $1 \mu \mathrm{L}$ of $1.0 \mathrm{mg} / \mathrm{mL}$ PI was added to each $0.6 \mathrm{~mL}$ cell suspension approximately 15 minutes before analysis. Cell 
viability was normalized to the untreated control (>97\% viability) and propidium iodide viability $\left(\mathrm{V}_{\mathrm{PI}}\right)$ was reported as mean \pm standard error of the mean. In addition, colony assays were performed to measure the cells' ability to proliferate and form colonies. Cells were plated in polystyrene disposable petri dishes (25384-092, VWR International, Mississauga, ON, CA) with $5 \mathrm{~mL}$ RPMI1640 and 10\% FBS and placed in a cell culture incubator at $37^{\circ} \mathrm{C}$. After 10 days the media was removed and the cells were stained using methylene blue dye for 15 minutes. Methylene blue dye was made by mixing $3 \mathrm{~g} / \mathrm{L}$ of methyl-blue powder (m4159, Sigma-Aldrich, Oakville, ON, CA) with a 50\% methanol (179957, Sigma-Aldrich, Oakville, ON, CA) and 50\% distilled water solution. For each treatment condition, 6-12 dishes were plated and stained. Following staining, the number of colonies per dish were counted manually and normalized to the untreated control samples. The clonogenic assay viability $\left(\mathrm{V}_{\mathrm{CA}}\right)$ is shown as mean \pm standard error of the mean.

Statistical differences were analyzed using Student t-test and viability differences were considered statistically significant with a p-value less than 0.05. In addition, the Bliss Independence Criteria was used to analyze synergism between treatment conditions (Bliss, 1939; Goldoni and Johansson, 2007). 


\subsection{Results}

\subsubsection{Cells centrifuged before laser}

Cell viability assessed with $\mathrm{PI}\left(\mathrm{V}_{\mathrm{PI}}\right)$ and colony assay $\left(\mathrm{V}_{\mathrm{CA}}\right)$ following treatment with laser, AuNR, USMB $\left(\mathrm{P}_{\text {neg }}=0.6 \mathrm{MPa}\right)$, AuNR+USMB, $(\mathrm{AuNR})_{\mathrm{c}}+\mathrm{L}$ and $(\mathrm{AuNR}+\mathrm{USMB})_{\mathrm{c}}+\mathrm{L}$, where the subscript $\mathrm{c}$ represents centrifugation prior to laser treatment, are shown in Figure 2.4A and 4B, respectively. No statistical differences were observed in $V_{P I}$ of cells treated with $(A u N R)_{c}+L$ compared to laser alone or AuNR alone (Figure 2.4A). A decrease in viability was achieved with USMB $(74 \pm 4 \%)$, AuNR+USMB $(75 \pm 2 \%)$, and $(A u N R+U S M B)_{c}+\mathrm{L}(69 \pm 3 \%)$ compared to the untreated control, however, the differences between the ultrasonically treated conditions were not statistically significant. The clonogenic viability $\left(\mathrm{V}_{\mathrm{CA}}\right)$ with the combined treatment of $(\mathrm{AuNR}+\mathrm{USMB})_{\mathrm{c}}+\mathrm{L}\left(\mathrm{V}_{\mathrm{CA}}=38 \pm 3 \%\right)$ was statistically lower than USMB $\left(\mathrm{V}_{\mathrm{CA}}=50 \pm 3 \%\right)$ and AuNR+USMB $\left(\mathrm{V}_{\mathrm{CA}}=48 \pm 3 \%\right)(\mathrm{p}<0.05)$ (Figure 2.4B). The combined treatment induced an additive effect on the clonogenic viability of cells. The expected additive effect of the combined treatments $(\mathrm{AuNR}) \mathrm{c}+\mathrm{L}\left(\mathrm{V}_{\mathrm{CA}}=64 \pm 4 \%\right)$ and $\mathrm{USMB}\left(\mathrm{V}_{\mathrm{CA}}=50 \pm 3 \%\right)$ on cell viability was $32 \pm 3 \%$ which was comparable to the experimental (AuNR+USMB)c+L viability of $38 \pm 3 \%$. In addition, the expected additive effect from $\mathrm{V}_{\mathrm{CA}}$ of laser and AuNR was calculated to be $61 \pm 11 \%$ which was similar to the experimental viability of $(\mathrm{AuNR})_{\mathrm{c}}+\mathrm{L}\left(\mathrm{V}_{\mathrm{CA}}=64 \pm 4 \%\right)$ indicating an additive effect. 


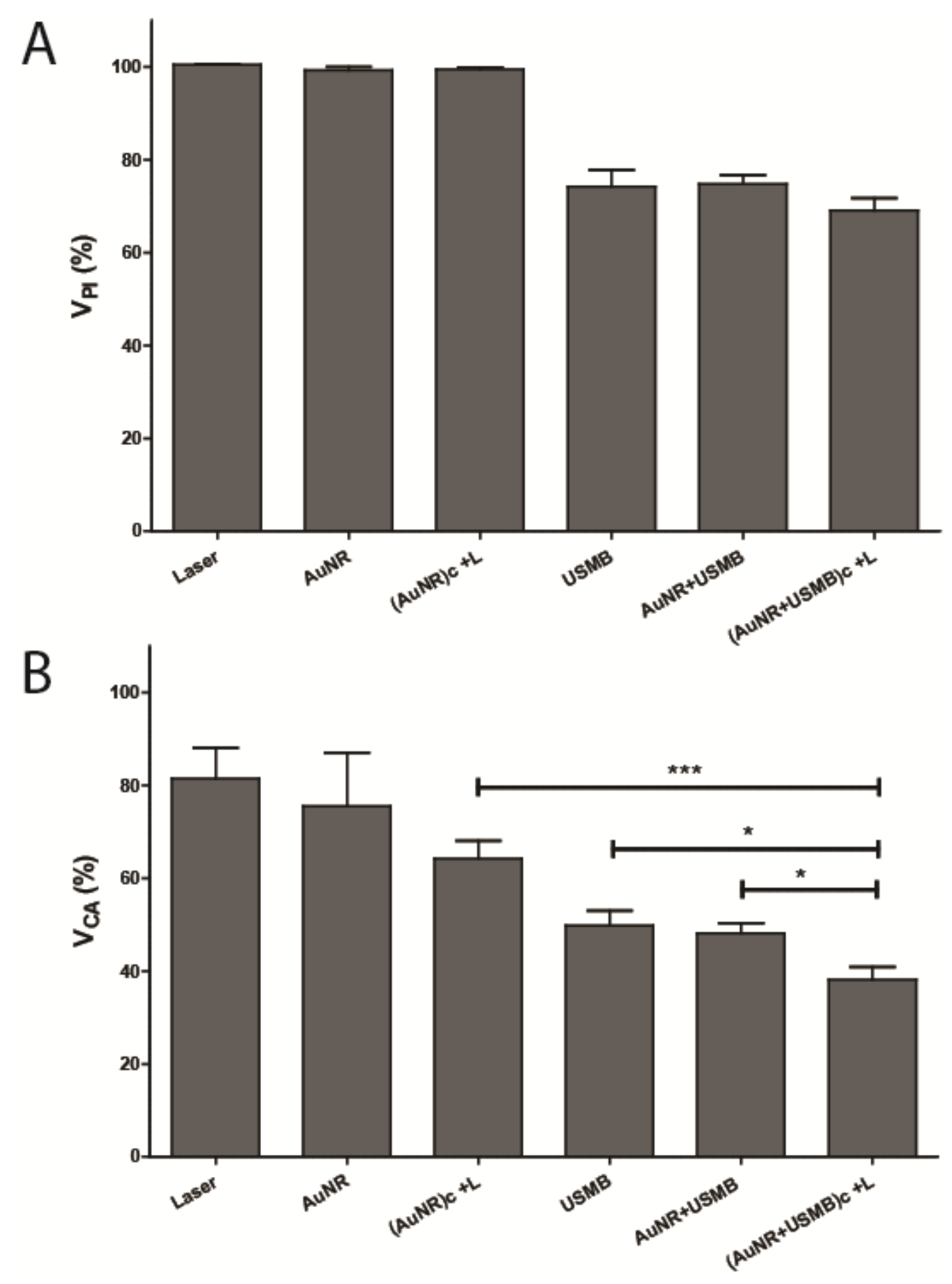

Figure 2.4 (A) Immediate viability $\left(\mathrm{V}_{\mathrm{PI}} ; \mathrm{n}=3\right)$ of centrifuged cells prior to laser irradiation assessed through flow cytometry and $(\mathbf{B})$ clonogenic viability $\left(\mathrm{V}_{\mathrm{CA}} ; \mathrm{n}=9\right)$. (AuNR) $\mathrm{c}+\mathrm{L}$ represents $3 \times 10^{11} \mathrm{np} / \mathrm{mL}$ of gold nanorods centrifuged prior to laser exposure for 3 minutes at $1.9 \mathrm{~W} / \mathrm{cm}^{2}$, USMB represents ultrasound and microbubbles at $0.6 \mathrm{MPa}$, AuNR+USMB represents $3 \times 10^{11} \mathrm{np} / \mathrm{mL}$ of gold nanorods present during USMB and (AuNR+USMB) $c+L$ represents samples exposed to AuNR+USMB and centrifuged prior to laser irradiation. A star $\left(^{*}\right)$ represents a student $t$-test significant difference with a $\mathrm{p}<0.05$ and 3 stars $(* * *)$ represents $\mathrm{p}<0.001$. 


\subsubsection{AuNR in suspension during laser}

Cell viability $-\mathrm{V}_{\mathrm{PI}}$ and $\mathrm{V}_{\mathrm{CA}}-$ following laser, AuNR, USMB $\left(\mathrm{P}_{\text {neg }}=0.6 \mathrm{MPa}\right)$, AuNR+USMB, (AuNR)+L and (AuNR+USMB)+L where samples were not centrifuged prior to laser treatment are shown in Figure 2.5A and 2.5B, respectively. A $\mathrm{V}_{\mathrm{PI}}$ of $22 \pm 3 \%$ was observed with $\mathrm{AuNR}+\mathrm{L}$ where AuNR were in suspension compared to $98 \pm 2 \%$ with $(\mathrm{AuNR})_{\mathrm{c}}+\mathrm{L}$

(centrifuged). The combined treatment of $(A u N R+L)+U S M B$ showed a significantly lower $V_{P I}$ of $12 \pm 1 \%$ compared to AuNR+L $(\mathrm{p}<0.05)$. In addition, a statistically significant difference $(\mathrm{p}<0.05)$ was observed between $(\mathrm{AuNR}+\mathrm{L})+\mathrm{USMB}$ and $(\mathrm{AuNR}+\mathrm{USMB})+\mathrm{L}$. However, the combined treatment of AuNR, USMB and L for all treatment orders showed no significant difference compared to the expected additive viability of $13 \pm 2 \%$ when combining AuNR $+\mathrm{L}$ $\left(\mathrm{V}_{\mathrm{PI}}=22 \pm 3 \%\right)$ and USMB $\left(\mathrm{V}_{\mathrm{PI}}=60 \pm 2 \% ; \mathrm{P}_{\text {neg }}=0.6 \mathrm{MPa}\right)$ which indicates an additive effect. Compared to $\mathrm{V}_{\mathrm{CA}}$ of $\mathrm{AuNR}+\mathrm{L}$ (Figure 2.5B), a statistically significant difference was observed between the combined treatment of AuNR, USMB and $\mathrm{L}$ for all treatment orders. $\mathrm{V}_{\mathrm{CA}}$ with $\mathrm{AuNR}+\mathrm{L}$ was $3 \pm 2 \%$ and with USMB alone $\left(\mathrm{P}_{\text {neg }}=0.6 \mathrm{MPa}\right)$ was $24 \pm 2 \%$. Similar to $\mathrm{V}_{\mathrm{PI}}$ results, $\mathrm{V}_{\mathrm{CA}}$ experimental results for $(\mathrm{AuNR}+\mathrm{USMB})+\mathrm{L}, \mathrm{USMB}+(\mathrm{AuNR}+\mathrm{L})$, and $(\mathrm{AuNR}+\mathrm{L})+\mathrm{USMB}$ showed no significant difference compared to the calculated additive value for any of the three treatment orders. 


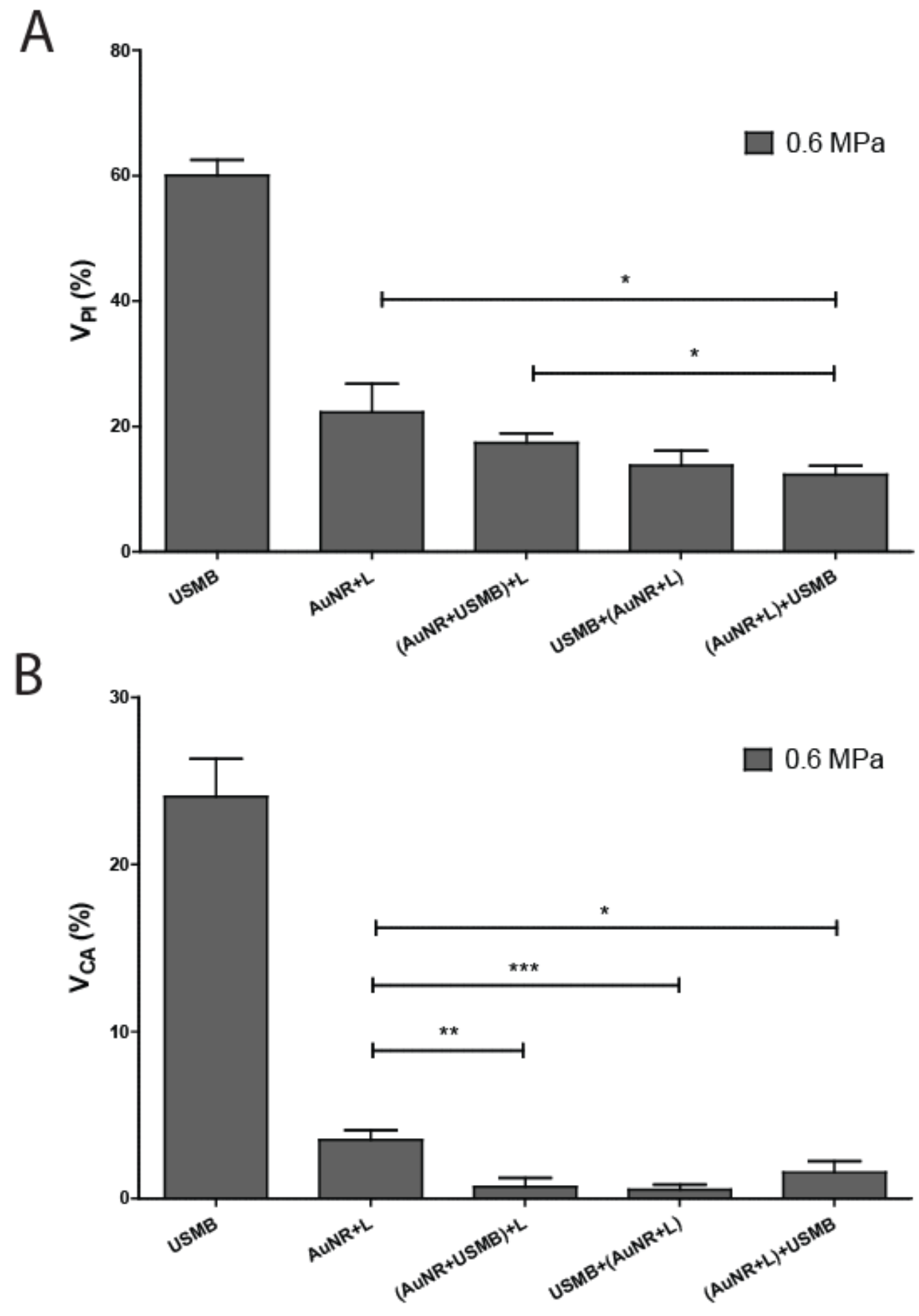

Figure 2.5 (A) Immediate viability $\left(\mathrm{V}_{\mathrm{PI}} ; \mathrm{n}=9\right)$ and $(\mathbf{B})$ Clonogenic Viability $\left(\mathrm{V}_{\mathrm{CA}} ; \mathrm{n}=12\right)$ of cells exposed to USMB at $0.6 \mathrm{MPa}$ in combination with AuNR and laser. AuNR represents $3 \times 10^{11} \mathrm{np} / \mathrm{mL}$ of gold nanorods present in solution with the cells. One star $(*)$ represents a student t-test significant difference with a $\mathrm{p}<0.05$, two stars $(* *)$ represent $\mathrm{p}<0.001$ and three stars $(* * *)$ represent $\mathrm{p}<0.0001$. 
The $\mathrm{V}_{\mathrm{PI}}$ and $\mathrm{V}_{\mathrm{CA}}$ of cells treated with AuNR, laser, USMB and their combination at a higher acoustic pressure of 1.0 MPa are shown in Figure 2.6A and 2.6B, respectively. As expected, cells exposed to $1.0 \mathrm{MPa}$ had a significantly lower viability than cells exposed to $0.6 \mathrm{MPa}$; a $\mathrm{V}_{\mathrm{PI}}$ of $60 \pm 2 \%$ and $42 \pm 3 \%$ were achieved at $0.6 \mathrm{MPa}$ and $1.0 \mathrm{MPa}(\mathrm{p}<0.001)$, respectively, and $\mathrm{V}_{\mathrm{CA}}$ of $5 \pm 1 \%$ was observed at $1.0 \mathrm{MPa}$ which is $19 \%$ lower than the $\mathrm{V}_{\mathrm{CA}}$ of USMB at $0.6 \mathrm{MPa}$ $(\mathrm{p}<0.0001)$. The $\mathrm{V}_{\mathrm{PI}}$ achieved with the combined treatment of AuNR, laser and USMB in different permutations was statistically different compared to AuNR+L ( $\left.\mathrm{V}_{\mathrm{PI}}=22 \pm 3 \%\right)$ and USMB $\left(\mathrm{V}_{\mathrm{PI}}=42 \pm 3 \% ; \mathrm{P}_{\text {neg }}=1.0 \mathrm{MPa}\right)$ individually (Figure 2.6A). USMB at $\mathrm{P}_{\text {neg }}$ of $1.0 \mathrm{MPa}$ induced an additive effect when combined with AuNR+L. The expected $V_{P I}$ of USMB combined with $\mathrm{AuNR}+\mathrm{L}$ was $9 \pm 2 \%$ and for $\mathrm{V}_{\mathrm{CA}}$ was $0.2 \pm 0.2 \%$ which was statistically similar to all treatment combinations indicating an additive effect at a $\mathrm{P}_{\text {neg }}$ of $1.0 \mathrm{MPa}$. 


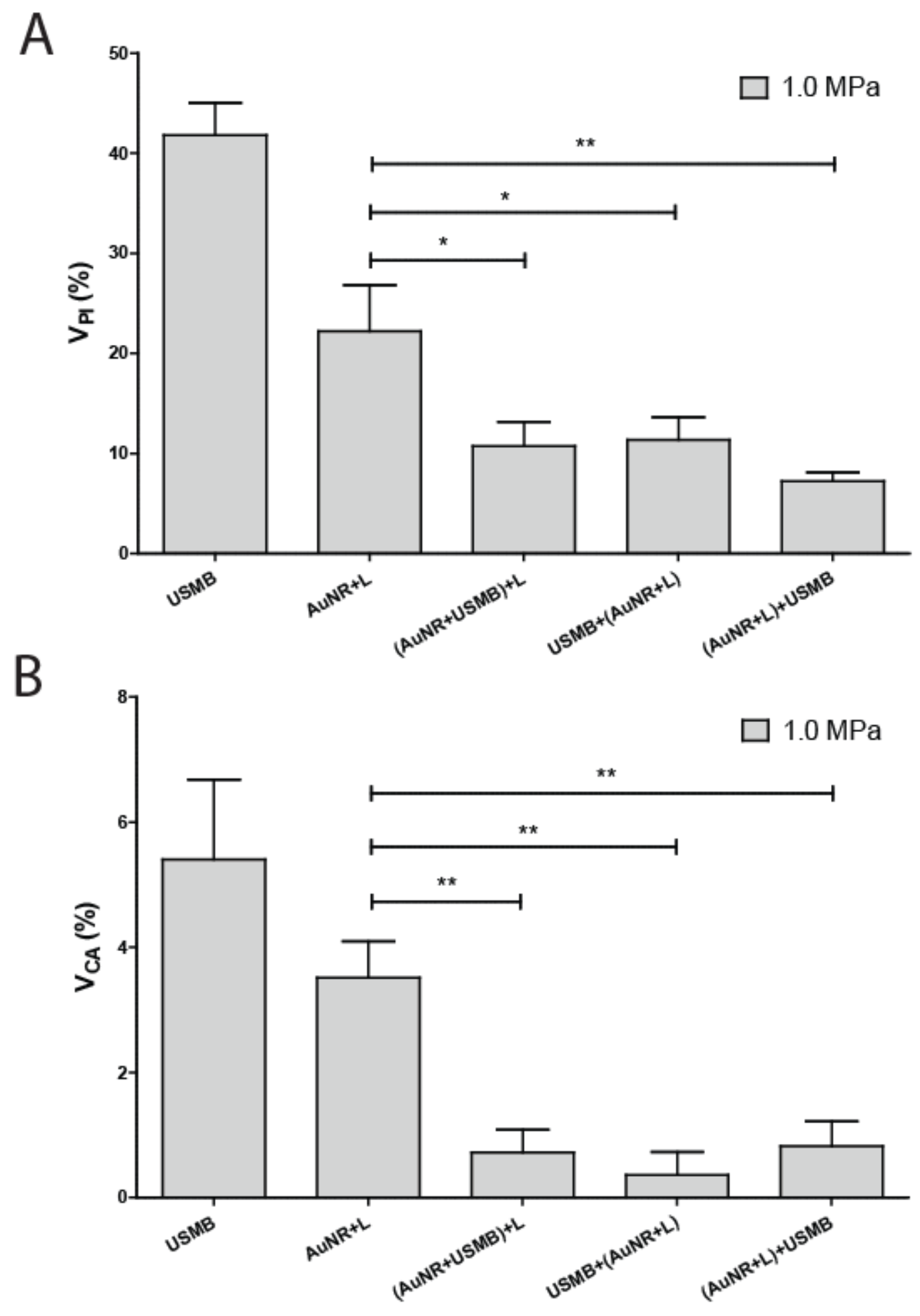

Figure 2.6 (A) Immediate viability $\left(\mathrm{V}_{\mathrm{PI}} ; \mathrm{n}=9\right)$ and $(\mathbf{B})$ Clonogenic Viability $\left(\mathrm{V}_{\mathrm{CA}} ; \mathrm{n}=12\right)$ of cells exposed to USMB at $1.0 \mathrm{MPa}$ in combination with AuNR and laser. AuNR represents $3 \times 10^{11} \mathrm{np} / \mathrm{mL}$ of gold nanorods present in solution with the cells. One star $(*)$ represents a student t-test significant difference with a $\mathrm{p}<0.05$ and two stars $(* *)$ represent $\mathrm{p}<0.001$. 


\subsubsection{USMB and Laser}

The $\mathrm{V}_{\mathrm{PI}}$ and $\mathrm{V}_{\mathrm{CA}}$ of cells treated with NIR laser and USMB $\left(\mathrm{P}_{\text {neg }}=0.6\right.$ and $\left.1.0 \mathrm{MPa}\right)$ are shown in Figure 2.7A and 2.7B, respectively. Generally, cell viability increased with the combined treatment of USMB and laser compared to USMB alone at lower acoustic pressures. $\mathrm{A} \mathrm{V}_{\mathrm{PI}}$ of $60 \pm 2 \%$ and $73 \pm 2 \%$ were achieved with USMB alone $\left(\mathrm{P}_{\text {neg }}=0.6 \mathrm{MPa}\right)$ and $\mathrm{L}+\mathrm{USMB}$, respectively; a statistically significant increase of $13 \%$ was observed in cell viability $(\mathrm{p}<0.01)$ (Figure 2.7A). Similarly, a higher cell $\mathrm{V}_{\mathrm{CA}}$ of $34 \pm 4 \%$ was achieved with USMB+L compared to $24 \pm 2 \%$ with USMB alone $\left(\mathrm{P}_{\text {neg }}=0.6 \mathrm{MPa}\right)$. However, at higher ultrasound pressure $\left(\mathrm{P}_{\text {neg }}=1.0\right.$ $\mathrm{MPa}$ ) no significant differences were observed in $\mathrm{V}_{\mathrm{PI}}$ and $\mathrm{V}_{\mathrm{CA}}$ of cells between USMB, $\mathrm{L}+\mathrm{USMB}$ and USMB+L. 

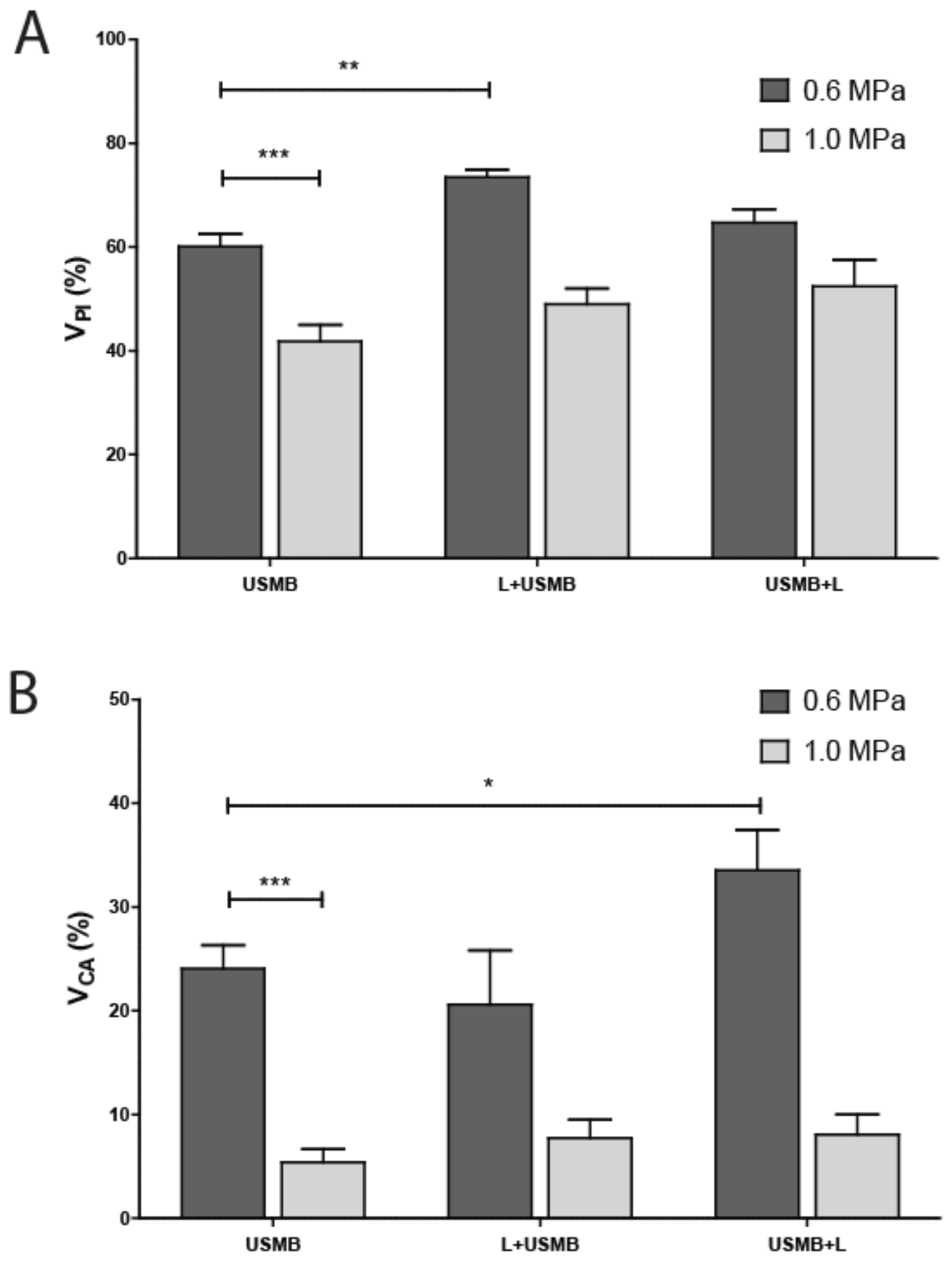

Figure 2.7 (A) Immediate viability $\left(\mathrm{V}_{\mathrm{PI}} ; \mathrm{n}=9\right)$ and $(\mathbf{B})$ Clonogenic Viability $\left(\mathrm{V}_{\mathrm{CA}} ; \mathrm{n}=12\right)$ of cells exposed to USMB at 0.6 and $1.0 \mathrm{MPa}$ in combination with laser before or after acoustic exposure. One star $(*)$ represents a student t-test significant difference with a $\mathrm{p}<0.05$, two stars $(* *)$ represent $\mathrm{p}<0.001$ and three stars $(* * *)$ represent $\mathrm{p}<0.0001$. 


\subsubsection{Thermal Dose}

The maximum temperature of the cell suspension during the laser treatment, which occurred at the 3 minute time point, and CEM43 of the combined treatments with AuNR and USMB are shown in Figure 2.8A and 2.8B, respectively. The maximum temperature ranged from $50^{\circ} \mathrm{C}$ to $53^{\circ} \mathrm{C}$ with the combined treatment of AuNR, USMB and L. A statistically lower temperature of $50 \pm 1{ }^{\circ} \mathrm{C}$ was achieved with (AuNR+USMB) $+\mathrm{L}$ compared to $53 \pm 1{ }^{\circ} \mathrm{C}$ with $\mathrm{USMB}+(\mathrm{AuNR}+\mathrm{L})$ at $\mathrm{P}_{\text {neg }}$ of $1.0 \mathrm{MPa}$. The maximum temperature achieved with $\mathrm{AuNR}+\mathrm{L}$ was $51.5 \pm 1^{\circ} \mathrm{C}$, whereas cells exposed to laser without AuNR had a maximum temperature below $39^{\circ} \mathrm{C}$ (data not shown). The cumulative equivalent minutes at $43^{\circ} \mathrm{C}(\mathrm{CEM} 43)$ - shown in a box plot with the median and interquartile range of the sample, and error bars representing the $10^{\text {th }}$ and $90^{\text {th }}$ percentile - ranged from a median CEM43 of 60 for samples treated with (AuNR+USMB)+L at $1.0 \mathrm{MPa}$ to a CEM43 of 349 for samples treated with USMB+(AuNR+L) at 1.0 MPa (Figure 2.8B). No statistical differences were observed between the maximum temperature of the combined treatments (AuNR, USMB and L) and AuNR+L with a median CEM43 of 135 and an interquartile range between 86 and 361 (Figure 2.8B). Scatter plots of median CEM43 with $\mathrm{V}_{\mathrm{PI}}$ and $\mathrm{V}_{\mathrm{CA}}$ for the different treatment conditions are shown in Figure 2.9A and 2.9B, respectively with error bars representing interquartile range. Although, viability decreased with increasing thermal dose (CEM43), Spearman's rank correlation coefficient showed no significant correlation for $\mathrm{V}_{\mathrm{PI}}$ or $\mathrm{V}_{\mathrm{CA}}$ at either ultrasound pressure with thermal dose. 

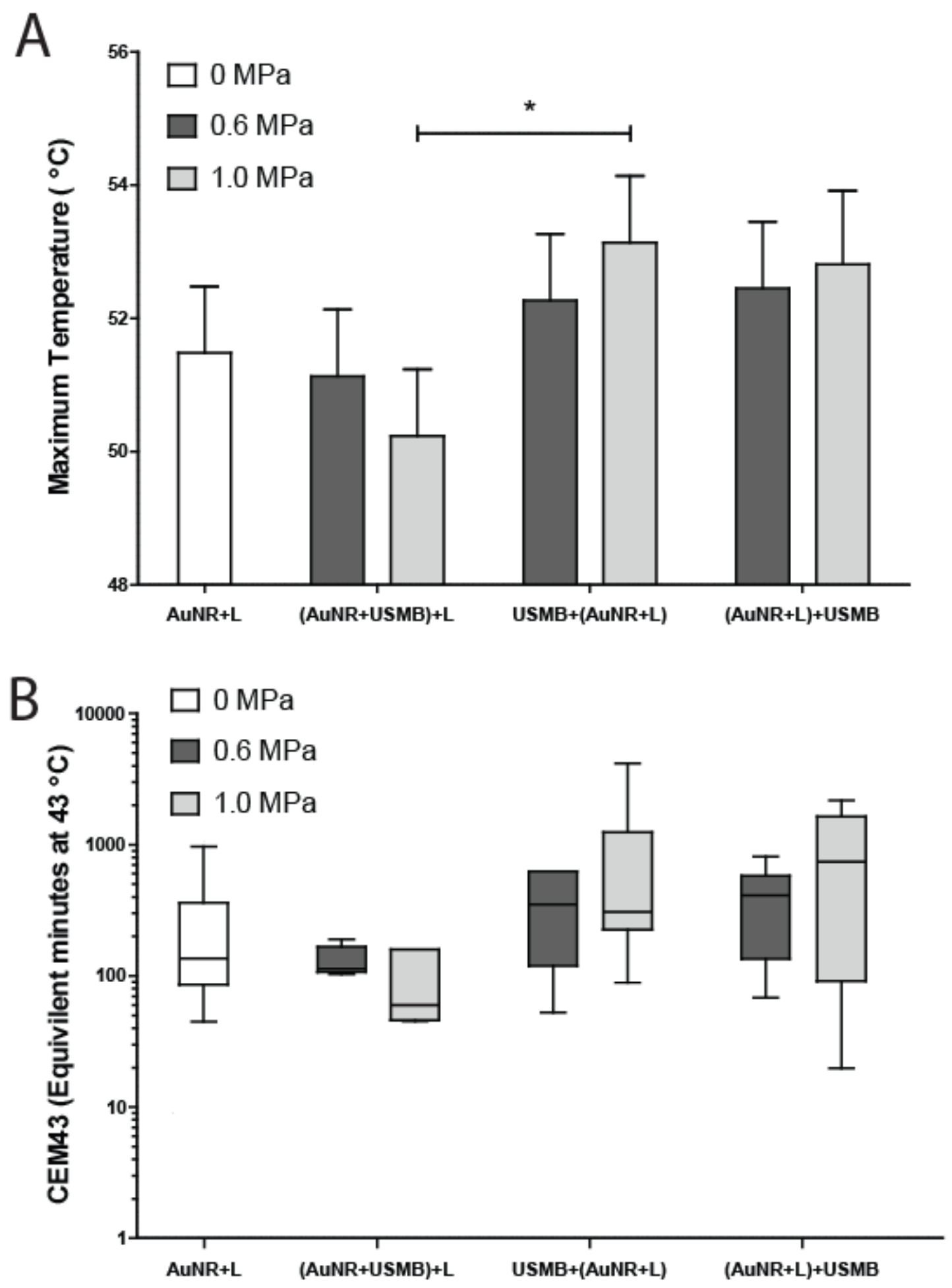

Figure 2.8 (A). Maximum sample temperature measured with a thermal camera after 3 minutes of laser therapy at $1.9 \mathrm{~W} / \mathrm{cm}^{2}$. (B) Cumulative equivalent minutes at $43^{\circ} \mathrm{C}(\mathrm{CEM} 43)$ during laser exposure. 


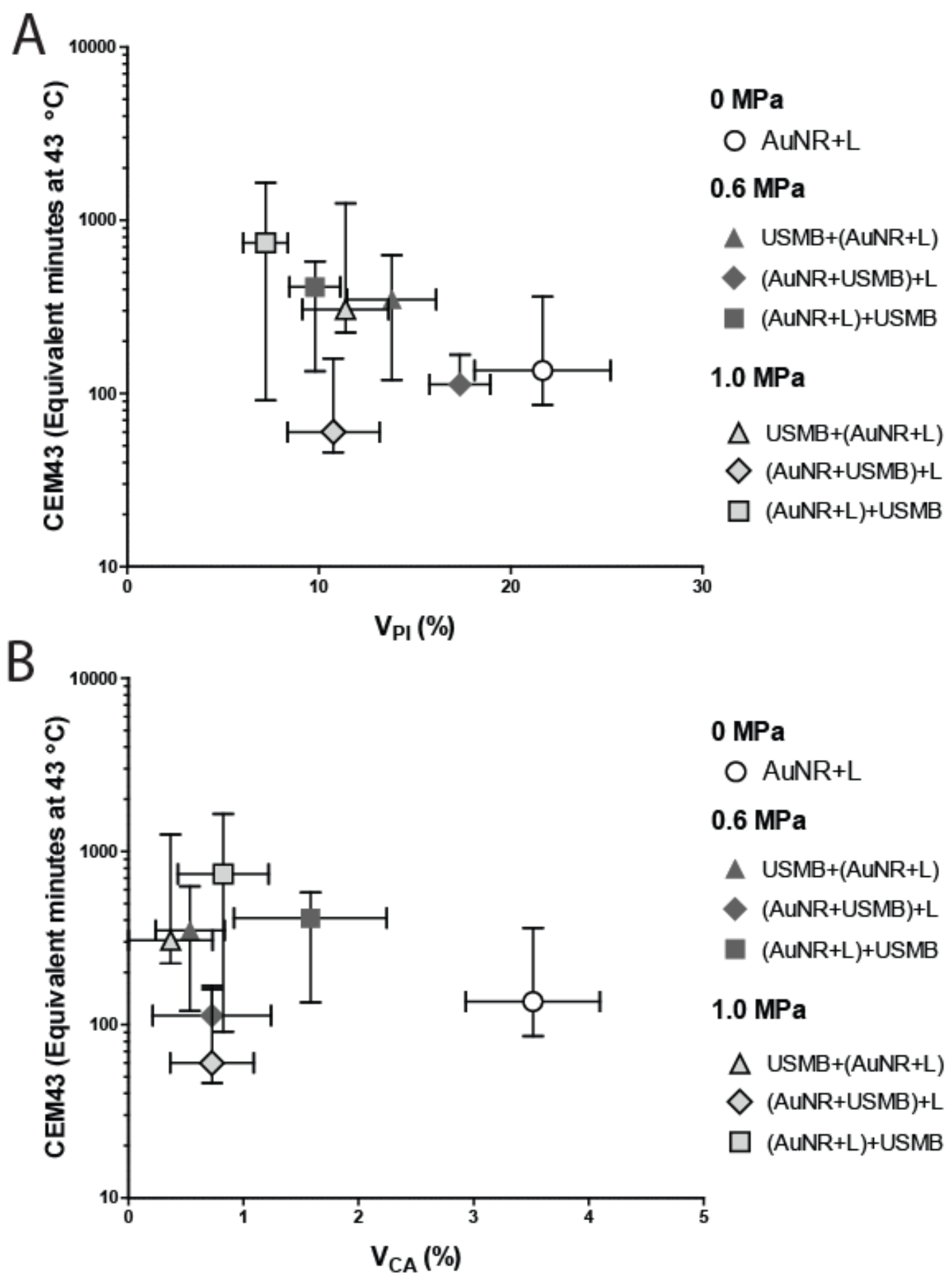

Figure 2.9 (A) $\mathrm{V}_{\mathrm{PI}}$ and (B) $\mathrm{V}_{\mathrm{CA}}$ relationship with CEM43 for samples containing AuNR at $3 \times 10^{11} \mathrm{np} / \mathrm{mL}$ in suspension during laser treatment with USMB at 0, 0.6 and 1.0 MPa and varying treatment order. 


\subsection{Discussion}

Ultrasound and microbubbles induced an additive effect on cell viability when combined with PEGylated AuNR laser therapy. In general, the effect on cell viability was independent of treatment order. The thermal dose did not appear to be an indicator of cell death for combined treatments with AuNR in suspension during laser therapy. However, when the AuNR were centrifuged out of suspension, the thermal dose was comparable to laser alone; the temperature remained below $39^{\circ} \mathrm{C}$ throughout laser treatment. This is the first study to show that in the absence of AuNR, NIR energy caused a protective effect on cell viability from ultrasound and microbubble exposure. Centrifuged cells that were exposed to AuNR also experienced a negligible thermal increase; however, they did not show the same protective effect.

The combined treatment of ultrasound-and-microbubble and laser therapy with gold nanoparticles, under the conditions studied, induced an additive effect on cell death suggesting independent mechanisms of killing cells. USMB causes mainly biomechanical effects on cells due to microbubble activity such as creating membrane pores that can either be transient or lead to cell death (Hu et al., 2013; Karshafian et al., 2010, 2009). The pores caused by USMB can recover within the order of minutes (Hu et al., 2013) showing that cellular recovery from physical damage begins to occur quickly. USMB also triggers biological effects such as apoptosis (Korosoglou et al., 2006; Zhang et al., 2008) and enhanced endocytosis (Meijering et al., 2009). Although acoustically induced membrane pores can be physically large enough to allow for the particles to pass through (Zhao et al., 2008; Zhou et al., 2009), larger membrane pores also correlate with increased cell death due to USMB alone (Hu et al., 2013) limiting the potential for an enhancement due to nanoparticle uptake. 
In contrast, $\mathrm{AuNR}+\mathrm{L}$ cause mainly thermal effects that can lead to protein denaturation, coagulation and necrosis (Despa et al., 2005). The thermal dose, or CEM43, is often used to approximate the treatment severity showing an exponential relationship with temperature and linear relationship with time (Pearce and Thomsen, 1995; Sherar et al., 2000). Thermal therapy can also induce bioeffects such as increased heat shock proteins to protect vital cellular proteins (Jakob et al., 1993; Moloney et al., 2012) and can trigger apoptosis (Schröder and Kaufman, 2005). Protective biological pathways that involve more sophisticated protein cascades such as heat-shock protein up-regulation, require a longer time on the order of hours, to induce their effect (Moloney et al., 2012). Changing the time delay between ultrasound and laser treatments may affect the cell viability due to possible protective effects of chaperone proteins (Jakob et al., 1993; Maglara et al., 2003). Considering there was an additive effect for both acoustic pressures tested, cells appear to be independently sensitive to thermal damage and mechanical damage under the treated conditions so combining the two treatments creates an enhanced, additive effect.

A previous study of ours showed a synergistic enhancement in cell death when AuNR laser thermal therapy was combined with ultrasound and microbubbles using CTAB coated gold nanorods (Tarapacki et al., 2013). It is likely that variations in the cell viability between the two studies could be attributed to the toxicity difference between the nanoparticle coatings. CTAB is positively charged and highly cytotoxic so it cannot safely be utilized in in vivo applications (Alkilany and Murphy, 2010). The PEG coating used in this study is biocompatible which limits uptake of AuNR through endocytosis but highly decreases cytotoxicity (Malugin and Ghandehari, 2010; Niidome et al., 2006). Other than the nanoparticle coating, another possible 
reason for differences between the two studies is a difference in cell lines used which can affect the bioeffects of USMB and intrinsic thermal resistance.

Variation of $\sim 3^{\circ} \mathrm{C}$ was observed in the temperature of the cell sample for the different treatment conditions. This may be due to the interaction of AuNR with the surrounding medium causing changes in the nanoparticles' optical properties (Alkilany and Murphy, 2010). Previous studies have shown that the optical absorption of gold nanoparticles in a solution changes with the dielectric properties of the medium and the interaction of the PEG coating with proteins and charges in the solution (Alkilany and Murphy, 2010; Maiorano et al., 2010). In addition, the size of the nanoparticle coating, has previously been found to change through time due to the interaction of the media (Maiorano et al., 2010; Nel et al., 2009). Following USMB, microbubble shell fragments in the media increase the lipid concentration and may affect the nanoparticle coating leading to changes in absorption properties and thermal dose. The $\mathrm{V}_{\mathrm{PI}}$ and $\mathrm{V}_{\mathrm{CA}}$ of the combined treatments showed no significant relationship with thermal dose, indicating that the CEM43 differences during the three minutes laser treatment did not appear to significantly affect cell viability.

The application of laser therapy enhanced cell viability following exposure to ultrasoundand-microbubbles. At a low intensity, NIR light has been found to stimulate cytochrome c oxidase and other mitochondrial chromophores resulting in increased metabolic activity leading to a protective effect on cells (Desmet et al., 2006). Low intensity NIR light has previously been used for photobiomodulation to precondition tissues for recovery prior to the application of severe treatments or surgeries (Wilmink et al., 2009). It is hypothesized that with an increased metabolic activity, cells may be able to repair membrane damage induced by ultrasound-andmicrobubbles. However, the protective effect of laser and USMB may limit the treatment 
efficacy of the combined treatment of AuNR, USMB and L. The failure to deliver a sufficient nanoparticle concentration may cause protective effects on cancer cells. However, gold nanoparticles can be monitored using photoacoustic and optical modalities prior to laser treatment (Huang et al., 2006; Jain et al., 2007; West and Halas, 2003). Although a protective effect of laser and USMB is not desirable in cancer therapy, the NIR light could be beneficial for gene therapy with ultrasound-microbubbles that aim to increase intracellular uptake while minimizing cell death.

\subsection{Conclusion}

The therapeutic effect of ultrasound-microbubbles with $\mathrm{mPEG}$ coated gold nanorod laser thermal therapy is additive with and without gold nanoparticles present in the solution. Thermal dose appeared not to be a predictor of cell death with the combined treatment of gold nanorod, ultrasound-microbubble and laser. In the absence of gold nanoparticles, NIR light can lead to protective effects on cells minimizing the damage caused by ultrasound and microbubbles. 


\subsection{References}

Al-Mahrouki, A.A., Karshafian, R., Giles, A., Czarnota, G.J., 2012. Bioeffects of UltrasoundStimulated Microbubbles on Endothelial Cells: Gene Expression Changes Associated with Radiation Enhancement In Vitro. Ultrasound Med. Biol. 38, 1958-1969.

Alkilany, A.M., Murphy, C.J., 2010. Toxicity and cellular uptake of gold nanoparticles: What we have learned so far? J. Nanoparticle Res. 12, 2313-2333.

Anderson, R.R., Parrish, J.A., 1981. The Optics of Human Skin. J Investig Dermatol 77, 13-19. Bliss, C.I., 1939. The toxicity of poisons applied jointly1. Ann. Appl. Biol. 26, 585-615.

Chang, S.-S., Shih, C.-W., Chen, C.-D., Lai, W.-C., Wang, C.R.C., 1999. The Shape Transition of Gold Nanorods. Langmuir 15, 701-709.

Chen, C.-L., Kuo, L.-R., Chang, C.-L., Hwu, Y.-K., Huang, C.-K., Lee, S.-Y., Chen, K., Lin, S.J., Huang, J.-D., Chen, Y.-Y., 2010. In situ real-time investigation of cancer cell photothermolysis mediated by excited gold nanorod surface plasmons. Biomaterials 31, 4104-4112.

Czarnota, G.J., Karshafian, R., Burns, P.N., Wong, S., Al Mahrouki, A., Lee, J.W., Caissie, A., Tran, W., Kim, C., Furukawa, M., 2012. Tumor radiation response enhancement by acoustical stimulation of the vasculature. Proc. Natl. Acad. Sci. 109, E2033-E2041.

Desmet, K.D., Paz, D.A., Corry, J.J., Eells, J.T., Wong-Riley, M.T.T., Henry, M.M., Buchmann, E.V., Connelly, M.P., Dovi, J.V., Liang, H.L., Henshel, D.S., Yeager, R.L., Millsap, D.S., Lim, J., Gould, L.J., Das, R., Jett, M., Hodgson, B.D., Margolis, D., Whelan, H.T., 2006. Clinical and experimental applications of NIR-LED photobiomodulation.

Photomed. Laser Surg. 24, 121-128.

Despa, F., Orgill, D.P., Neuwalder, J., Lee, R.C., 2005. The relative thermal stability of tissue macromolecules and cellular structure in burn injury. Burns 31, 568-577.

Doinikov, A.A., Bouakaz, A., 2010. Theoretical investigation of shear stress generated by a contrast microbubble on the cell membrane as a mechanism for sonoporation. J. Acoust. Soc. Am. 128, 11-19.

Duvshani-Eshet, M., Benny, O., Morgenstern, A., Machluf, M., 2007. Therapeutic ultrasound facilitates antiangiogenic gene delivery and inhibits prostate tumor growth. Mol. Cancer Ther. 6, 2371-2382.

Gad, S.C., Sharp, K.L., Montgomery, C., Payne, J.D., Goodrich, G.P., 2012. Evaluation of the Toxicity of Intravenous Delivery of Auroshell Particles (Gold-Silica Nanoshells). Int. J. Toxicol. 31, 584-594.

Goertz, D.E., Todorova, M., Mortazavi, O., Agache, V., Chen, B., Karshafian, R., Hynynen, K., 2012. Antitumor effects of combining docetaxel (taxotere) with the antivascular action of ultrasound stimulated microbubbles. PloS One 7, e52307.

Goldoni, M., Johansson, C., 2007. A mathematical approach to study combined effects of toxicants in vitro: Evaluation of the Bliss independence criterion and the Loewe additivity model. Toxicol. In Vitro 21, 759-769.

Grossman, J.H., McNeil, S.E., 2012. Nanotechnology in cancer medicine. Phys. Today 65, 3842.

Hauck, T.S., Jennings, T.L., Yatsenko, T., Kumaradas, J.C., Chan, W.C.W., 2008. Enhancing the toxicity of cancer chemotherapeutics with gold nanorod hyperthermia. Adv. Mater. 20, 3832-3838.

Hu, Y., Wan, J.M.F., Yu, A.C.H., 2013. Membrane Perforation and Recovery Dynamics in Microbubble-Mediated Sonoporation. Ultrasound Med. Biol. 39, 2393-2405. 
Huang, X., El-Sayed, I.H., Qian, W., El-Sayed, M.A., 2006. Cancer cell imaging and photothermal therapy in the near-infrared region by using gold nanorods. J. Am. Chem. Soc. 128, 2115-2120.

Jain, P.K., ElSayed, I.H., El-Sayed, M.A., 2007. Au nanoparticles target cancer. Nano Today 2, 18-29.

Jain, P.K., Lee, K.S., El-Sayed, I.H., El-Sayed, M.A., 2006. Calculated absorption and scattering properties of gold nanoparticles of different size, shape, and composition: Applications in biological imaging and biomedicine. J. Phys. Chem. B 110, 7238-7248.

Jakob, U., Gaestel, M., Engel, K., Buchner, J., 1993. Small heat shock proteins are molecular chaperones. J. Biol. Chem. 268, 1517-1520.

Karshafian, R., Bevan, P.D., Williams, R., Samac, S., Burns, P.N., 2009. Sonoporation by Ultrasound-Activated Microbubble Contrast Agents: Effect of Acoustic Exposure Parameters on Cell Membrane Permeability and Cell Viability. Ultrasound Med. Biol. 35, 847-860.

Karshafian, R., Samac, S., Bevan, P.D., Burns, P.N., 2010. Microbubble mediated sonoporation of cells in suspension: clonogenic viability and influence of molecular size on uptake. Ultrasonics 50, 691-697.

Korosoglou, G., Hardt, S.E., Bekeredjian, R., Jenne, J., Konstantin, M., Hagenmueller, M., Katus, H.A., Kuecherer, H., 2006. Ultrasound exposure can increase the membrane permeability of human neutrophil granulocytes containing microbubbles without causing complete cell destruction. Ultrasound Med. Biol. 32, 297-303.

Lal, S., Clare, S.E., Halas, N.J., 2008. Nanoshell-enabled photothermal cancer therapy: Impending clinical impact. Acc. Chem. Res. 41, 1842-1851.

Lau, I.P., Chen, H., Wang, J., Ong, H.C., Leung, K.C.-F., Ho, H.P., Kong, S.K., 2012. In vitro effect of CTAB-and PEG-coated gold nanorods on the induction of eryptosis/erythroptosis in human erythrocytes. Nanotoxicology 6, 847-856.

Lipka, J., Semmler-Behnke, M., Sperling, R.A., Wenk, A., Takenaka, S., Schleh, C., Kissel, T., Parak, W.J., Kreyling, W.G., 2010. Biodistribution of PEG-modified gold nanoparticles following intratracheal instillation and intravenous injection. Biomaterials 31, 65746581.

Maglara, A.A., Vasilaki, A., Jackson, M.J., McArdle, A., 2003. Damage to developing mouse skeletal muscle myotubes in culture: Protective effect of heat shock proteins. J. Physiol. 548, 837-846.

Maiorano, G., Sabella, S., Sorce, B., Brunetti, V., Malvindi, M.A., Cingolani, R., Pompa, P.P., 2010. Effects of cell culture media on the dynamic formation of protein-nanoparticle complexes and influence on the cellular response. ACS Nano 4, 7481-7491.

Malugin, A., Ghandehari, H., 2010. Cellular uptake and toxicity of gold nanoparticles in prostate cancer cells: a comparative study of rods and spheres. J. Appl. Toxicol. 30, 212-217.

Meijering, B.D.M., Juffermans, L.J.M., Van Wamel, A., Henning, R.H., Zuhorn, I.S., Emmer, M., Versteilen, A.M.G., Paulus, W.J., Van Gilst, W.H., Kooiman, K., De Jong, N., Musters, R.J.P., Deelman, L.E., Kamp, O., 2009. Ultrasound and microbubble-targeted delivery of macromolecules is regulated by induction of endocytosis and pore formation. Circ. Res. 104, 679-687.

Moloney, T.C., Hoban, D.B., Barry, F.P., Howard, L., Dowd, E., 2012. Kinetics of thermally induced heat shock protein 27 and 70 expression by bone marrow-derived mesenchymal stem cells. Protein Sci. 21, 904-909. 
Nel, A.E., Mädler, L., Velegol, D., Xia, T., Hoek, E.M.V., Somasundaran, P., Klaessig, F., Castranova, V., Thompson, M., 2009. Understanding biophysicochemical interactions at the nano-bio interface. Nat. Mater. 8, 543-557.

Niidome, T., Yamagata, M., Okamoto, Y., Akiyama, Y., Takahashi, H., Kawano, T., Katayama, Y., Niidome, Y., 2006. PEG-modified gold nanorods with a stealth character for $<\mathrm{i}>$ in vivo</i> applications. J. Controlled Release 114, 343-347.

Nofiele, J.I.T., Karshafian, R., Furukawa, M., Al Mahrouki, A., Giles, A., Wong, S., Czarnota, G.J., 2013. Ultrasound-activated microbubble cancer therapy: Ceramide production leading to enhanced radiation effect in vitro. Technol. Cancer Res. Treat. 12, 1-8.

Pearce, J., Thomsen, S., 1995. Rate Process Analysis of Thermal Damage, in: Welch, A., Gemert, M.C. (Eds.), Optical-Thermal Response of Laser-Irradiated Tissue, Lasers, Photonics, and Electro-Optics. Springer US, pp. 561-606.

Qiu, Y., Luo, Y., Zhang, Y., Cui, W., Zhang, D., Wu, J., Zhang, J., Tu, J., 2010. The correlation between acoustic cavitation and sonoporation involved in ultrasound-mediated DNA transfection with polyethylenimine (PEI) in vitro. J. Controlled Release 145, 40-48.

Sasaki, D.T., Dumas, S.E., Engleman, E.G., 1987. Discrimination of viable and non-viable cells using propidium iodide in two color immunofluorescence. Cytometry 8, 413-420.

Schröder, M., Kaufman, R.J., 2005. The mammalian unfolded protein response.

Sherar, M.D., Moriarty, J.A., Kolios, M.C., Chen, J.C., Peters, R.D., Ang, L.C., Hiks, R.S., Henkelman, R.M., Bronskill, M.J., Kucharcyk, W., 2000. Comparison of thermal damage calculated using magnetic resonance thermometry, with magnetic resonance imaging post-treatment and histology, after interstitial microwave thermal therapy of rabbit brain. Phys. Med. Biol. 45, 3563-3576.

Simpson, C.A., Agrawal, A.C., Balinski, A., Harkness, K.M., Cliffel, D.E., 2011. Short-chain PEG mixed monolayer protected gold clusters increase clearance and red blood cell counts. ACS Nano 5, 3577-3584.

Sokolov, K., Tam, J., Tam, J., Travis, K., Larson, T., Aaron, J., Harrison, N., Emelianov, S., Johnston, K., 2009. Cancer imaging and therapy with metal nanoparticles. Conf. Proc. Annu. Int. Conf. IEEE Eng. Med. Biol. Soc. IEEE Eng. Med. Biol. Soc. Conf. 2009, 2005-2007.

Tarapacki, C., Kumaradas, C., Karshafian, R., 2013. Enhancing laser thermal-therapy using ultrasound-microbubbles and gold nanorods of in vitro cells. Ultrasonics 53, 793-798.

Todorova, M., Agache, V., Mortazavi, O., Chen, B., Karshafian, R., Hynynen, K., Man, S., Kerbel, R.S., Goertz, D.E., 2013. Antitumor effects of combining metronomic chemotherapy with the antivascular action of ultrasound stimulated microbubbles. Int. J. Cancer 132, 2956-2966.

Wang, L., Jiang, X., Ji, Y., Bai, R., Zhao, Y., Wu, X., Chen, C., 2013. Surface chemistry of gold nanorods: Origin of cell membrane damage and cytotoxicity. Nanoscale 5, 8384-8391.

Wang, S., Lu, W., Tovmachenko, O., Rai, U.S., Yu, H., Ray, P.C., 2008. Challenge in understanding size and shape dependent toxicity of gold nanomaterials in human skin keratinocytes. Chem. Phys. Lett. 463, 145-149.

West, J.L., Halas, N.J., 2003. Engineered nanomaterials for biophotonics applications: Improving sensing, imaging, and therapeutics.

Wilmink, G.J., Opalenik, S.R., Beckham, J.T., Abraham, A.A., Nanney, L.B., MahadevanJansen, A., Davidson, J.M., Jansen, E.D., 2009. Molecular imaging-assisted optimization 
of hsp70 expression during laser-induced thermal preconditioning for wound repair enhancement. J. Invest. Dermatol. 129, 205-216.

Wu, J., Ross, J.P., Chiu, J.-F., 2002. Reparable sonoporation generated by microstreaming. J. Acoust. Soc. Am. 111, 1460-1464.

Zhang, P., Gao, Y.-H., Liu, Z., Liu, P., Tan, K.-B., 2008. Mechanism of apoptosis of vascular smooth muscle cells induced by ultrasound irradiation combined with microbubbles. Chin. J. Med. Imaging Technol. 24, 1681-1684.

Zhao, Y.-Z., Luo, Y.-K., Lu, C.-T., Xu, J.-F., Tang, J., Zhang, M., Zhang, Y., Liang, H.-D., 2008. Phospholipids-based microbubbles sonoporation pore size and reseal of cell membrane cultured in vitro. J. Drug Target. 16, 18-25.

Zhou, Y., Kumon, R.E., Cui, J., Deng, C.X., 2009. The Size of Sonoporation Pores on the Cell Membrane. Ultrasound Med. Biol. 35, 1756-1760. 


\section{Summary}

The purpose of this study was to investigate the effect of biologically compatible PEG coated AuNR laser thermal therapy with ultrasound and microbubbles in vitro. It was expected that exposing cells to USMB with AuNR present in solution prior to laser irradiation would yield an improved therapeutic effect compared to other treatment combinations due to AuNR uptake into cells allowing for heat to be emitted closer to the nucleus and vital cell organelles.

In the study MDA-MB-231 cells in suspension were exposed to PEG coated AuNR and an $810 \mathrm{~nm}$ laser. The bulk temperature during laser treatment was monitored using a thermal camera. Cells were exposed to $500 \mathrm{kHz}$ pulsed ultrasound at 2 different acoustic pressures; 0.6 and 1.0 MPa peak negative pressure. In addition, cells were either treated with AuNR centrifuged out of solution prior to laser treatment or left in suspension. After treatment, cell viability was monitored using propium iodide with flow cytometry $\left(\mathrm{V}_{\mathrm{PI}}\right)$ and through colony assays $\left(\mathrm{V}_{\mathrm{CA}}\right)$.

$\mathrm{V}_{\mathrm{PI}}$ and $\mathrm{V}_{\mathrm{CA}}$ results both show an additive effect between USMB and AuNR+L for centrifuged and non-centrifuged cells with only minor differences due to treatment order. Under the conditions studied, the results show the effect of USMB and AuNR+L are independent. As expected, increased ultrasound pressure resulted in lower cell viability for all treatment conditions. A protective effect causing an increase in cell viability by approximately $10 \%$ was observed for cells exposed to laser and USMB without any AuNR interaction. However, this protective effect was only seen in the absence of AuNR and not observed for centrifuged samples exposed to AuNR and laser. Sample temperature due to laser exposure with AuNR in 
suspension was statistically similar to the temperature of cells exposed to only AuNR+L for all combined treatment samples. However, there was a statistically significant difference between samples exposed to AuNR with USMB prior to laser $\left(50 \pm 1^{\circ} \mathrm{C}\right)$ compared to USMB followed by $\mathrm{AuNR}+\mathrm{L}\left(53 \pm 1^{\circ} \mathrm{C}\right)$ at a $\mathrm{P}_{\text {neg }}$ of $1.0 \mathrm{MPa}$.

The hypothesis that gold nanorod laser thermal therapy combined with ultrasound and microbubbles enhances cell death in vitro compared to either treatment on its own was proven correct. Overall, there was an additive therapeutic effect on cells exposed to the combined treatment of AuNR+L and USMB regardless of treatment order and whether AuNR was centrifuged or remained in suspension. 


\section{Future work}

\subsection{In vitro: Heat shock protein 70}

\section{Introduction}

Ultrasound and microbubbles in combination with PEG coated gold nanorod thermal therapy have additive, independent effects on cell viability. Understanding how the combined treatment affects the cellular response can provide further insight into cellular behavior and mechanism of cell death. Considering both mechanical and thermal damage can trigger heat shock protein (Hsp) production to protect cells from subsequent damage (Nylandsted et al., 2000; Rylander et al., 2005), it is possible that USMB and AuNR+L both trigger Hsp production which is important to consider during treatment planning. Heat shock protein 70 (Hsp70) is an antiapoptotic, ATP-dependent chaperone protein that is mainly stress induced in normal cells (Nylandsted et al., 2000; Rylander et al., 2005). In many cancerous tumors including breast, prostate, colon and hepatocellular cancers, cells have a higher Hsp70 baseline which may be partially responsible for the cells' survival advantage (Nylandsted et al., 2000). Monitoring the Hsp70 after treatment can provide insight into the cellular response after ultrasound and microbubble assisted gold nanorod thermal therapy. Preliminary studies with Hsp have been performed that monitor Hsp70 levels of USMB, AuNR+L and the combined treatment AuNR+USMB+L through time for centrifuged samples. 


\section{Methodology}

The heat shock proteins (HSP70) in cells treated with USMB ( $\mathrm{P}_{\text {neg }}$ of $\left.0.6 \mathrm{MPa}\right)$, $(\mathrm{AuNR}) \mathrm{c}+\mathrm{L}$ and $(\mathrm{AuNR}+\mathrm{USMB}) \mathrm{c}+\mathrm{L}$ was assessed immediately and 3 hours after the treatment. Heated positive control samples were placed in a $42^{\circ} \mathrm{C}$ water bath for 90 minutes with 90 minutes recovery at $37^{\circ} \mathrm{C}$ which according to previous studies by Wang et al. (Wang et al., 2003) result in significant Hsp70 activation. Following treatment, cells were fixed with $4 \%$ paraformaldehyde (28906, VWR International) and incubated at $37^{\circ} \mathrm{C}$ for 10 minutes followed by 1 minute on ice. Cells were permeabilized by centrifuging and re-suspending cells in $90 \%$ methanol followed by 30 minute incubation on ice. An incubation buffer was prepared by diluting $0.5 \mathrm{~g}$ bovine serum albumin (BSA, A9418, Sigma-Aldrich) with $100 \mathrm{~mL}$ PBS. Cells were washed with $3 \mathrm{~mL}$ incubation buffer twice and blocked with $100 \mu \mathrm{L}$ incubation buffer for 10 minutes. A volume of $2 \mu$ L HSP70 antibody (Alexa Fluor ${ }^{\circledR} 488$ conjugate, Cell Signaling Technology, Whitby, ON, CA) was added to each sample and incubated at room temperature for 1 hour in the dark. After incubation, cells were washed and resuspended in $0.5 \mathrm{~mL}$ PBS. Samples were individually analyzed with flow cytometry measuring fluorescence of at least 5000 cells per sample. 


\section{Preliminary results and discussion}

Intracellular heat shock protein 70 (Hsp70) was assessed in this study using flow cytometry. Figure 4.1 shows intracellular Hsp70 antibody intensity histograms at 0 and 3 hours after treatment with USMB, (AuNR)c+L and $($ AuNR+USMB $) c+L$. As expected the heated control (red line) which showed cells heated for 90 minutes at $42^{\circ} \mathrm{C}$ with 90 minutes recovery at $37^{\circ} \mathrm{C}$ had an increased Hsp70 intensity compared to the untreated control (black line).

0 hours

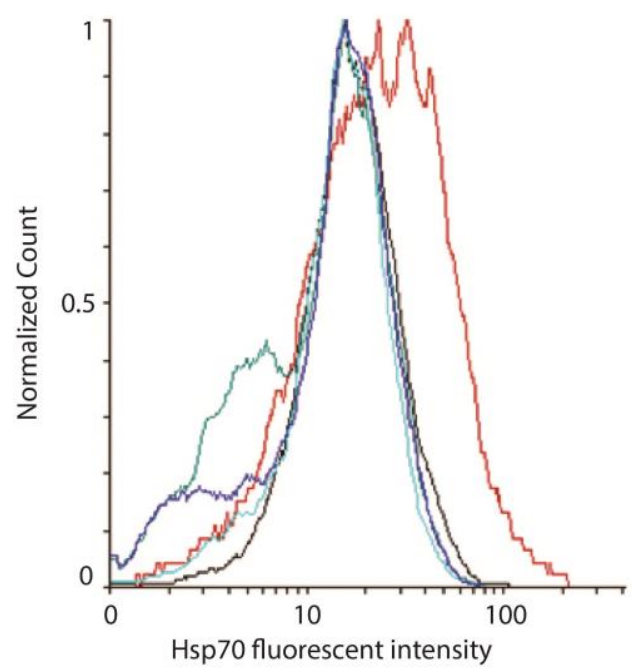

3 hours

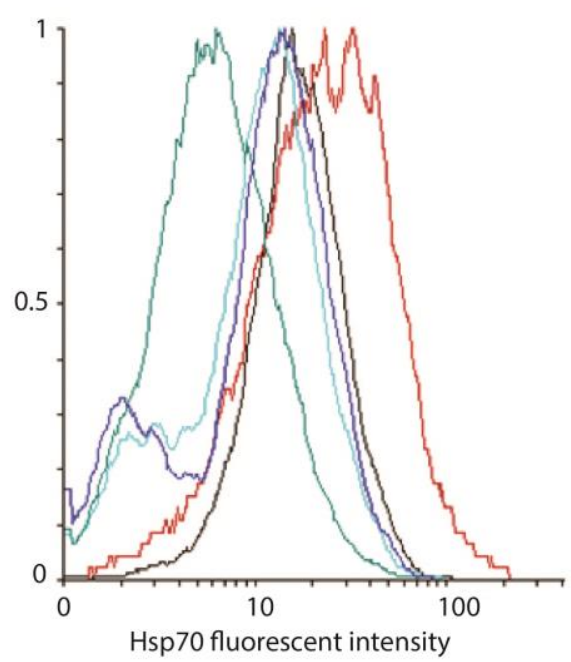

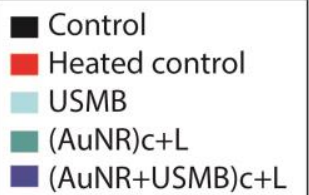

Contro

Heated control $($ AuNR) $C+L$

$($ AuNR+USMB) $\mathrm{C}+\mathrm{L}$

Figure 4.1 (A) Hsp70 for centrifuged samples immediately after treatment and (B) 3 hours after treatment.

Immediately after treatment, $(\mathrm{AuNR}) \mathrm{c}+\mathrm{L}$ and $(\mathrm{AuNR}+\mathrm{USMB}) \mathrm{c}+\mathrm{L}$ populations showed a decrease in intensity. Three hours after treatment, USMB samples (light blue) also showed a decreased intensity compared to the untreated control that was similar to the $($ AuNR+USMB)c+L (purple) samples. The largest decrease in Hsp70 was observed for $(\mathrm{AuNR}) \mathrm{c}+\mathrm{L}$ samples compared to USMB and (AuNR+USMB)c+L. 
Intracellular Hsp70 levels were measured in this study to determine whether they contribute to the mechanism behind cell death after USMB or AuNR+L treatments. The Hsp70 levels in the heated control increased compared to the untreated control which confirms previous studies that Hsp70 is up-regulated from hyperthermia (Gourgou et al., 2010; Lang et al., 2000; Wang et al., 2003). The changes in Hsp70 for all treated samples decreased compared to the control showing clear difference between the USMB and laser treatments compared to cell heating in a water bath.

The decreased levels of Hsp70 in the treated conditions shows the response is different from the hyperthermic Hsp70 up-regulation response. The depletion of intracellular Hsp70 detected after ultrasonically stimulated microbubble treatment and thermal therapy may be due to protein release from the cell or translocating to the cell membrane to stabilize the effected membrane proteins (Zhou et al., 2008). The method of cell membrane permeabilization chosen in this study used the organic solvent methanol which causes cell membrane protein coagulation. For this reason the detected Hsp70 intensity was only intracellular and did not include membrane bound proteins.

A possible explanation for the decrease in Hsp70 from USMB treatment may be due to leakage out of membrane pores. Similarly sized $70 \mathrm{kDa}$-FITC dextran can be used as a cell permeability marker for USMB showing that the pores created are large enough for $70 \mathrm{kDa}$ molecules to enter cells (Karshafian et al., 2009). Theoretically, $70 \mathrm{kDa}$ heat shock proteins could also fit through the pores causing an overall decrease in cellular Hsp70. However, considering the pores for surviving cells only remain open on the order of minutes (Hu et al., 2013), enhanced Hsp70 leakage would help explain the decrease in Hsp70 intensity only at the 0 hour time point. 
For AuNR+L samples Hsp70 decreased after treatment. Since the AuNR from the solution were removed prior to laser treatment the sample temperature remained below $39^{\circ} \mathrm{C}$ which is not within the hyperthermic range; $40-45^{\circ} \mathrm{C}$ (Habash et al., 2006). The NIR laser or nanoparticles that remained around the cells could have caused localized cell membrane damage which was not enough to trigger Hsp70 up-regulation, but enough to signify a response for Hsp70 to protect the plasma membrane in a similar way to photodynamic therapy treatment (Zhou et al., 2008).

Previous studies have indicated that cancerous cells typically express overabundance of Hsp70 and heat shock protein depletion can be lethal to them (Nylandsted et al., 2000) . Hsp70 has been found to bind to apoptosis protease activating factor-1 (Apaf-1) in cancer cells which prevents the formation of an apoptosome and subsequently apoptosis (Ravagnan et al., 2001; Ruchalski et al., 2006) . The observed decrease in intracellular Hsp70 may contribute to apoptosis which has been found to increase after USMB (Zhong et al., 2011). However, further studies are required to determine whether the Hsp70 are being released from the cells or translocate to cell membranes. 


\subsection{In vivo: Microvascular perfusion}

\section{Introduction}

Ultrasound in combination with microbubbles (USMB) has been found to enhance drug delivery and effectiveness in vivo (Ferrara et al., 2007; Sheikov et al., 2004). Ultrasound waves can be focused to within a few millimeters which can be used to target a tumor. Although the effect of USMB has been observed in previous studies (Ferrara et al., 2007; Hernot and Klibanov, 2008; Unger et al., 2004), a thorough understanding of the mechanism on a microvascular level is still unknown. Considering microbubbles are typically injected into the vasculature, they interact primarily with the endothelial cells of small vessels, capillary structures, and red blood cells. Previous studies have shown that USMB causes capillary rupture (Skyba et al., 1998) and enhanced local drug delivery (Li et al., 2004; Price et al., 1998; Sheikov et al., 2004; Stieger et al., 2007). In response to USMB, vasoconstriction can occur in the exposed area which can lead to a localized reduction in blood flow (Hirokawa et al., 2007; Raymond et al., 2007; Vykhodtseva et al., 2007). The vascular effects caused by USMB can be transient under controlled treatment conditions allowing for recovery (Hirokawa et al., 2007). In addition, USMB cause biological effects such as increasing the radiosensitivity (Tran et al., 2012) and chemosensitivity (Tomizawa et al., 2001) of a treatment area.

Typically tumors have weak, dilated, tortuous, microvasculature that supplies the rapidly dividing cancer cells with nourishment and oxygen (Carmeliet and Jain, 2000). Changes in microvasculature can affect tumor health and behavior. Correlating microbubble behavior with microvascular perfusion and damage may help develop treatment planning which is important for combinational therapies with drugs or radiation. Preliminary work has been completed 
investigating the microvascular perfusion changes due to varying acoustic pressure on a fertilized chicken egg membrane (Chorioallantoic memberane, CAM).

\section{Methodology}

All chicken embryos were handled in accordance with the institutional Animal Care and Use Committee approval. Fertilized White Leghorn chicken embryos were purchased from Fleming Chicks Limited (Beamsville, Ontario, CA) and incubated horizontally in an Octagon ${ }^{\circledR} 40$ (Brinsea, C. Botkin Enterprises Ltd., CA) rocking egg incubator at $37.5^{\circ} \mathrm{C}$ with $60 \%$ relative humidity. After 72 hours of incubation the eggs were cracked and the embryos were transferred into sterile, $10 \mathrm{~cm}$, extra-deep petri dishes (Fisher Scientific, \#08-757-11). Squares of approximately 15 x $15 \mathrm{~cm}$ of low-density polyethylene (LDPE, $0.025 \mathrm{~mm}$, Goodfellow, Cambridge limited) membrane were cut, sterilized with $70 \%$ ethanol and placed inside the dishes prior to embryo addition to allow for easy embryo removal and transfer into the ultrasound setup (Figure 4.2). Approximately $15 \mathrm{~mL}$ of Alpha MEM media was added to each dish to provide a source of calcium during bone mineralization to increase embryonic survival rate (Schomann et al., 2013). A $2 \mathrm{~mm}$ hole was soldered into each Petri dish lid approximately $1 \mathrm{~cm}$ away from the edge to allow for gas circulation and prevent suffocation. After cracking, the embryos were placed inside a $37^{\circ} \mathrm{C}$ humidified incubator to grow and mature. At day 12 after fertilization, Hamburger-Hamilton stage 38-40, embryos were removed from the incubator and treated. Post treatment and imaging all embryos were sacrificed.

Prior to each CAM injection, a 1:1 mixture of $70 \mathrm{kDa}$ fluorescein isothiocyanate-dextran (5 $\mu \mathrm{g} / \mathrm{mL}$, FITC) and Definity microbubbles was created. A $100 \mu \mathrm{L}$ bolus injection of the mixture was injected into a large anterior vein of the CAM using a 30 gauge bent needle. When the 
needle tip was removed, sterile gauze was placed over the injection site to limit leakage. After injection, the embryo was removed from the petri dish with the LDPE membrane and transferred into the ultrasound treatment chamber.

Figure 4.2 shows the ultrasound treatment setup. The CAM was placed on a dish with an acoustically permeable LDPE membrane along the bottom and was secured on top of a $37^{\circ} \mathrm{C}$ distilled water tank. The setup was placed on a computer-controlled stage and under an upright microscope (Axiotechvario 100HD; Zeiss, Germany). FITC dextran allowed for clear visualization of the vasculature and the focal level was adjusted to the capillary plexus. FITC was excited at $495 \mathrm{~nm}$ by monochromatic light (Polychrome IV; T.I.L.L. Photonics, Germany) and filtered through dichroic and emission filters (FT 510, LP520; Zeiss). Videos were recorded using a silicone intensified tube camera (CF 8/4 FMC; Germany) and recorded on digital videotape.

A $500 \mathrm{kHz}$ ultrasound transducer (IL0.510HP, Valpey Fisher Inc, Hopkinton, MA) and 20x objective lens were confocally aligned to allow for simultaneous treatment and imaging in the focal area. The ultrasound treatment sequence was generated by a waveform generator and consisted of an 8 cycle pulse, $1 \mathrm{kHz}$ pulse repetition frequency and was alternated between on and off every 5 seconds for 2 minutes treatment duration. The CAM were treated at varying pressures of 160, 240 or $320 \mathrm{kPa}$ and fluorescent videos and images were taken before, during ultrasound exposure and up to 15 minutes after treatment. 


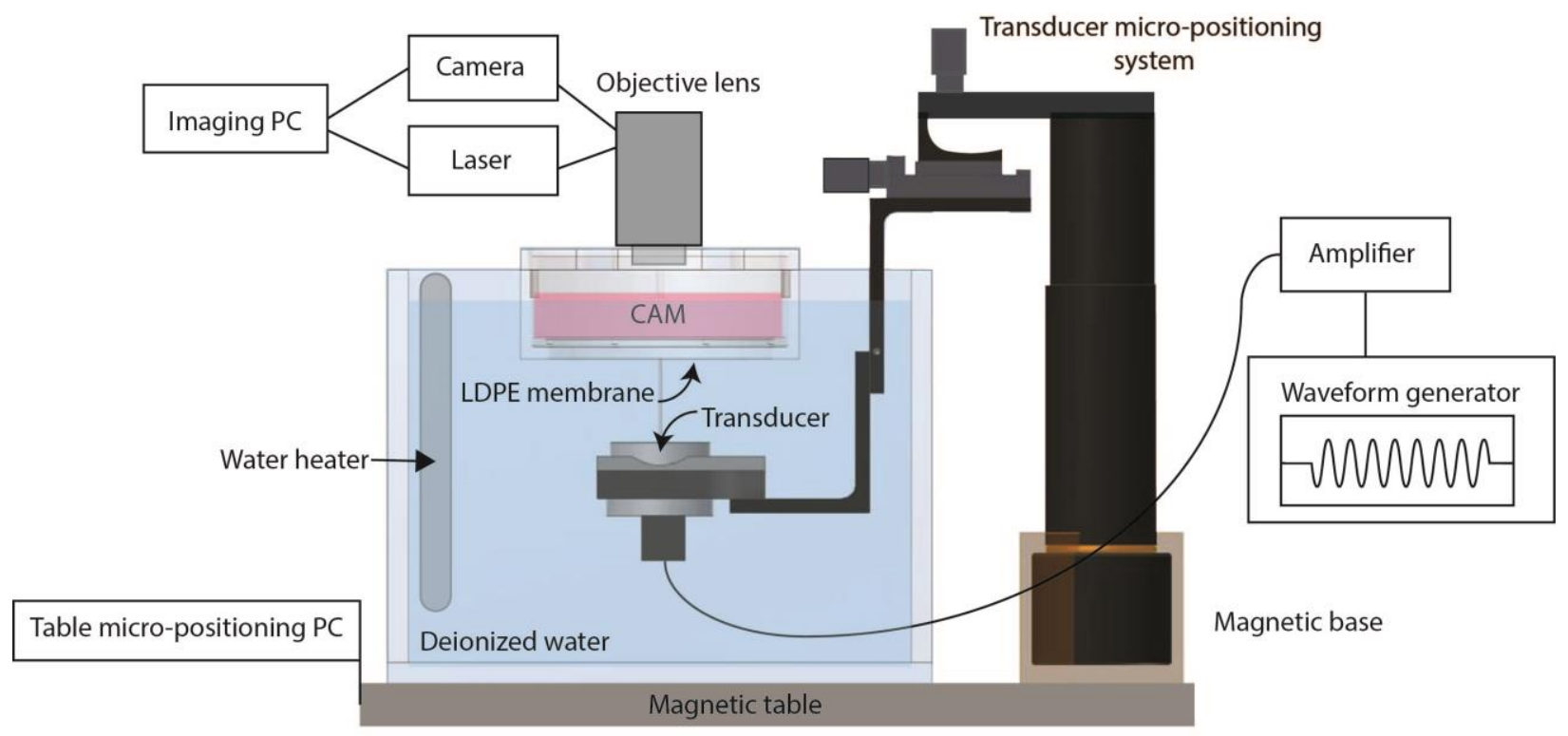

Figure 4.2. CAM treatment setup. An ultrasound transducer and objective lens of a fluorescent microscope were confocally aligned and focused on a microvascular region of interest on the CAM. The transducer and bottom of the CAM dish were submerged in a $37^{\circ} \mathrm{C}$ deionized water bath.

Throughout this study perfusion was monitored by looking at the flow of red blood cells within the microvasculature. With FITC-dextran illuminating the inter-vascular fluid, blood flow was observed by the movement of dark objects within the vasculature. The black objects were assumed to be red blood cells; impermeable to the FITC dextran dye. Their circulation within the blood and their motion signified perfused vasculature.

Video screen shots for different times after treatment were overlaid on top of each other using Adobe Illustrator and a consistent region of interest (ROI) was chosen. The total capillary path length was measured manually for individual snapshots through time to determine perfusion changes. 


\section{Preliminary results}

The results show vascular perfusion for CAM exposed to 160, 240 and $320 \mathrm{kPa}$ for 2 minutes treatment time. Time 0 refers to immediately before treatment and time 2 minutes refers to immediately after the treatment. Figure 4.3 shows CAM treated at $160 \mathrm{kPa}$ with a region of interest (ROI) of $0.034 \mathrm{~mm}^{2}$. By visual inspection of the ROI through time, no significant changes to perfusion were visible. The capillary length and capillary length per area are shown in Table 4.1. At time points $0,1,2,5$ and 15 minutes after the start of a 2 minute treatment the variations in capillary length/ area were less than $0.01 \mu \mathrm{m}^{-1}$.

Table 4.1 Capillary length of CAM treated at $160 \mathrm{kPa}$

\begin{tabular}{|c|c|c|}
\hline Time $(\mathrm{min})$ & Capillary length $(\mathrm{mm})$ & Capillary length/ area $\left(\mu \mathrm{m}^{-1}\right)$ \\
\hline 0 & 3.78 & 0.11 \\
\hline 1 & 3.66 & 0.11 \\
\hline 2 & 3.53 & 0.10 \\
\hline 5 & 3.84 & 0.11 \\
\hline 15 & 3.52 & 0.10 \\
\hline
\end{tabular}



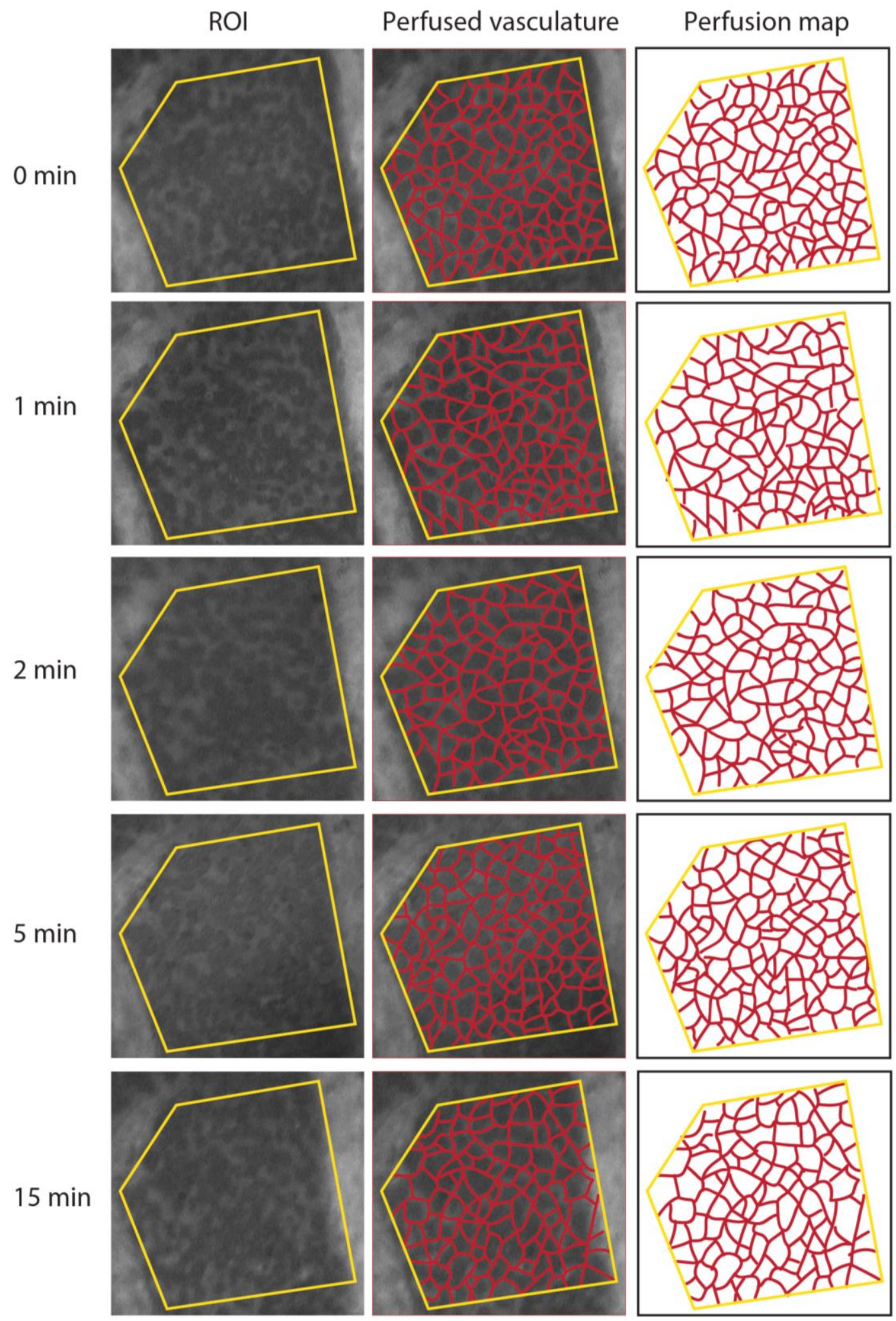

Figure 4.3 Vascular perfusion of CAM exposed to $160 \mathrm{kPa}$ for 2 minutes at time $0,1,2,5$, and 15 minutes after the start of treatment. ROI is $0.034 \mathrm{~mm}^{2}$. 
Figure 4.4 shows CAM treated at $240 \mathrm{kPa}$ through time and Table 4.2 shows the capillary length and capillary length/area. The 0 time point is missing due to unstable embryo motion at the start of treatment. A decrease in vascular perfusion was observed from 1 to 10 minutes after the start of treatment however, at the 15 minute time point perfusion increased. Capillaries began to regained perfusion close to the venules above and to the left of the ROI. Another example of a temporal perfusion change throughout ultrasound treatment at $240 \mathrm{kPa}$ is shown in Figure 4.5. Clusters of blood cells appeared to obstruct blood flow in an arteriole with a $17 \mu \mathrm{m}$ diameter (bottom middle of each frame; directly below the arrow) and connecting capillaries. Black arrows point towards clusters that are obstructing blood flow and are visible after 10 seconds of ultrasound exposure. 

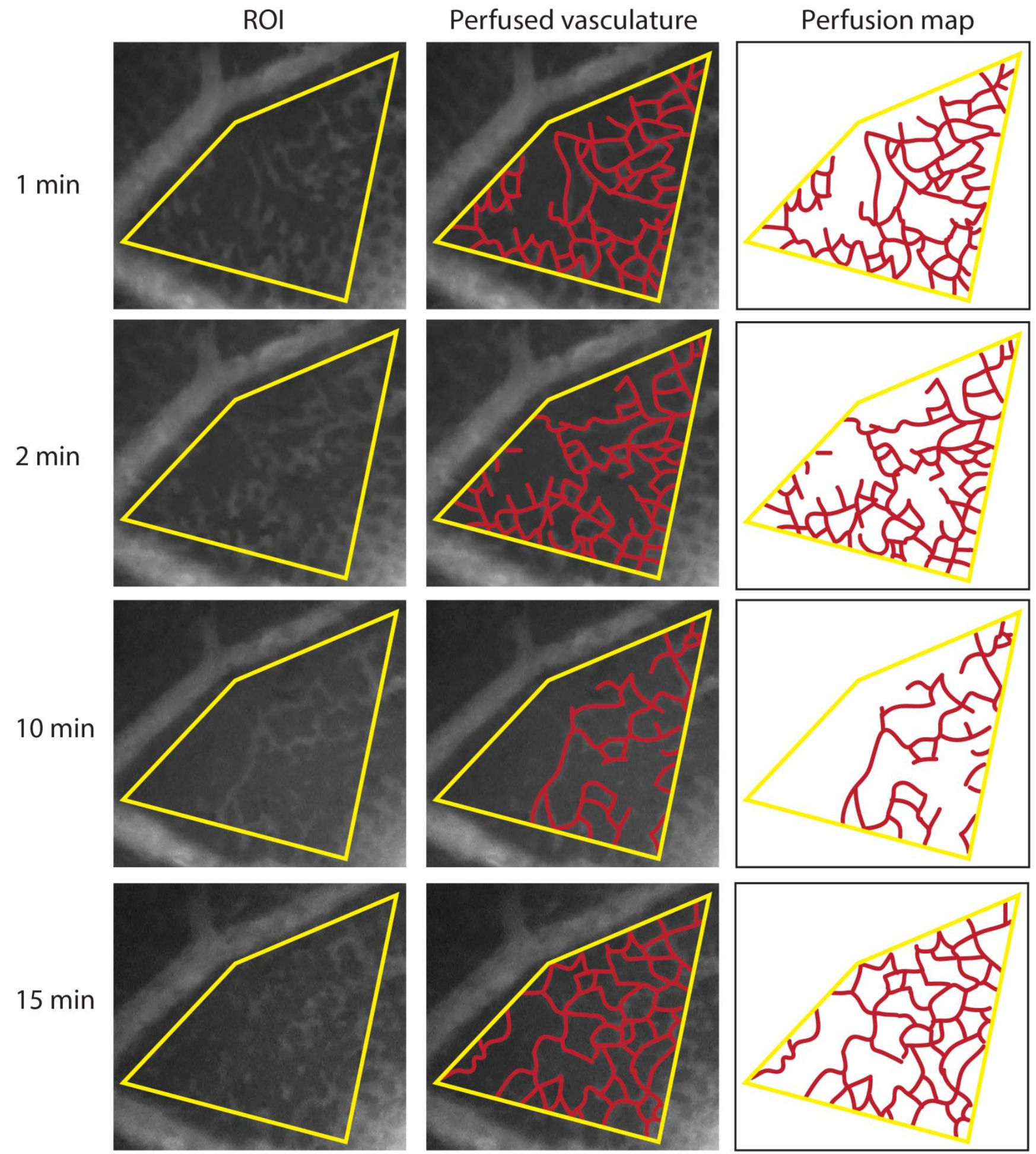

Figure 4.4 Vascular perfusion of CAM exposed to $240 \mathrm{kPa}$ for 2 minutes at time 1,2,10, and 15 minutes after the start of treatment. ROI is $0.030 \mathrm{~mm}^{2}$. 
Table 4.2 Capillary length of CAM treated at $240 \mathrm{kPa}$

\begin{tabular}{|c|c|c|}
\hline Time (min) & Capillary length $(\mathrm{mm})$ & Capillary length / ${\operatorname{area~}\left(\mathrm{um}^{-1}\right)}^{-1}$ \\
\hline 1 & 2.02 & 0.068 \\
\hline 2 & 1.97 & 0.066 \\
\hline 10 & 1.04 & 0.035 \\
\hline 15 & 1.84 & 0.062 \\
\hline
\end{tabular}
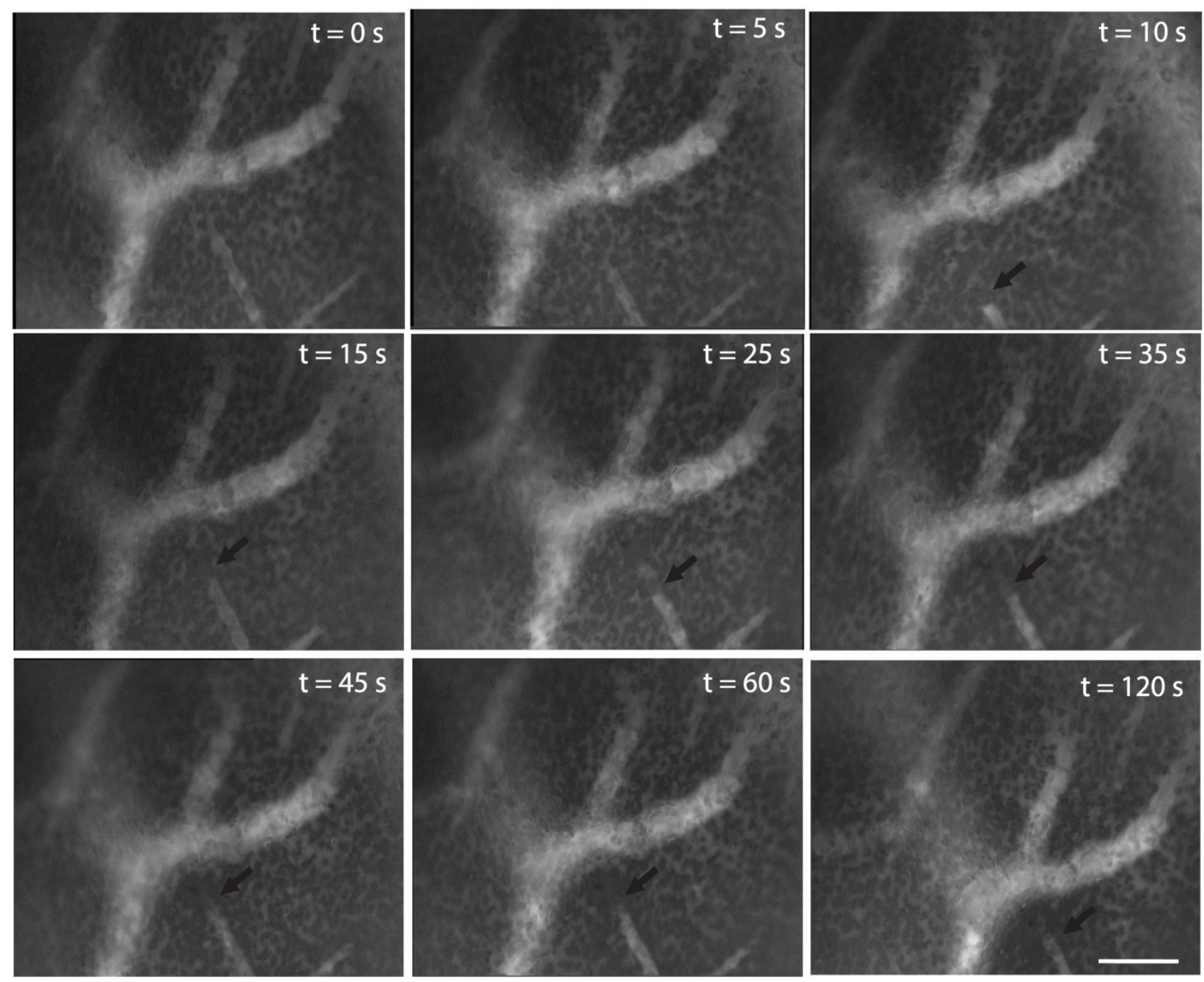

Figure 4.5 Micrographs through time after ultrasound and microbubble exposure at $240 \mathrm{kPa}$. Arrows point to vascular blockage which is visible after 10 seconds of ultrasound exposure. White scale bar represents $100 \mu \mathrm{m}$. 
Figure 4.6 shows vascular perfusion due to $320 \mathrm{kPa}$ ultrasound exposure pressure with capillary length through time recorded in Table 4.3. Within the ROI perfusion remained fairly constant during the 2 minute treatment but decreased considerably at the 15 minute time point. In addition, the distance between the surrounding vessels was measured along the top-right border of the ROI and decreased $76 \%$ from $270 \mu \mathrm{m}$ to $206 \mu \mathrm{m}$ from the 0 to $15^{\text {th }}$ time points. This shows a local tissue contraction within the ROI.

Figure 4.7 compares the effect of pressure on capillary length per area through time. It shows a minimal effect on vasculature treated at $160 \mathrm{kPa}$, a clear decrease in perfusion through time at $320 \mathrm{kPa}$ and a temporary decrease in perfusion for vasculature treated at $240 \mathrm{kPa}$. 

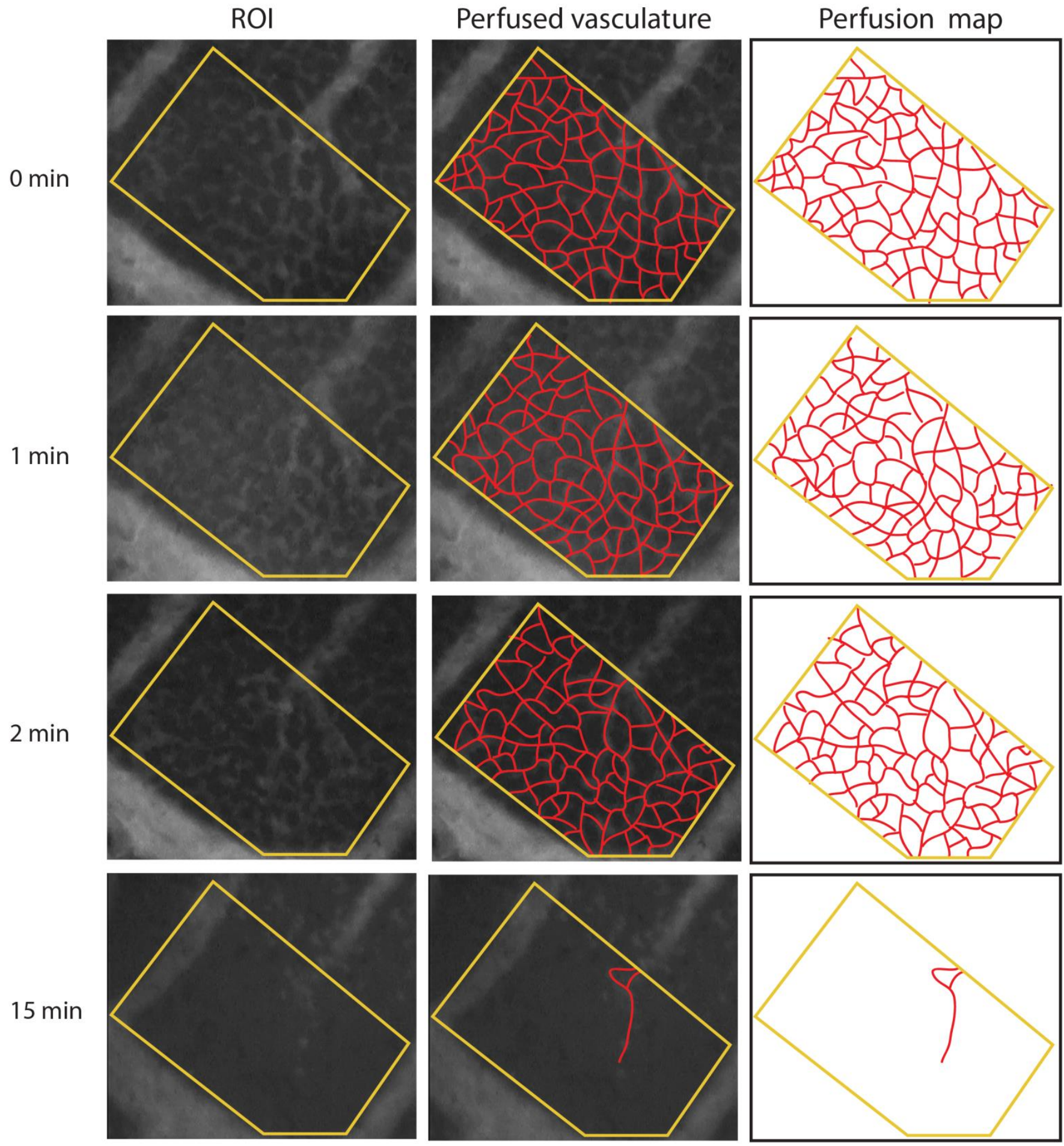

Figure 4.6 Vascular perfusion of CAM exposed to $320 \mathrm{kPa}$ for 2 minutes at time 0,1 , 2, and 15 minutes after the start of treatment. ROI is $0.031 \mathrm{~mm}^{2}$. 
Table 4.3 Capillary length of CAM treated at $320 \mathrm{kPa}$

\begin{tabular}{|c|c|c|}
\hline Time (min) & Capillary length $(\mathrm{mm})$ & ${\text { Capillary length/ area }\left(\mu \mathrm{m}^{-1}\right)}^{-1}$ \\
\hline 0 & 3.18 & 0.100 \\
\hline 1 & 3.12 & 0.097 \\
\hline 2 & 3.06 & 0.096 \\
\hline 15 & 0.13 & 0.004 \\
\hline
\end{tabular}

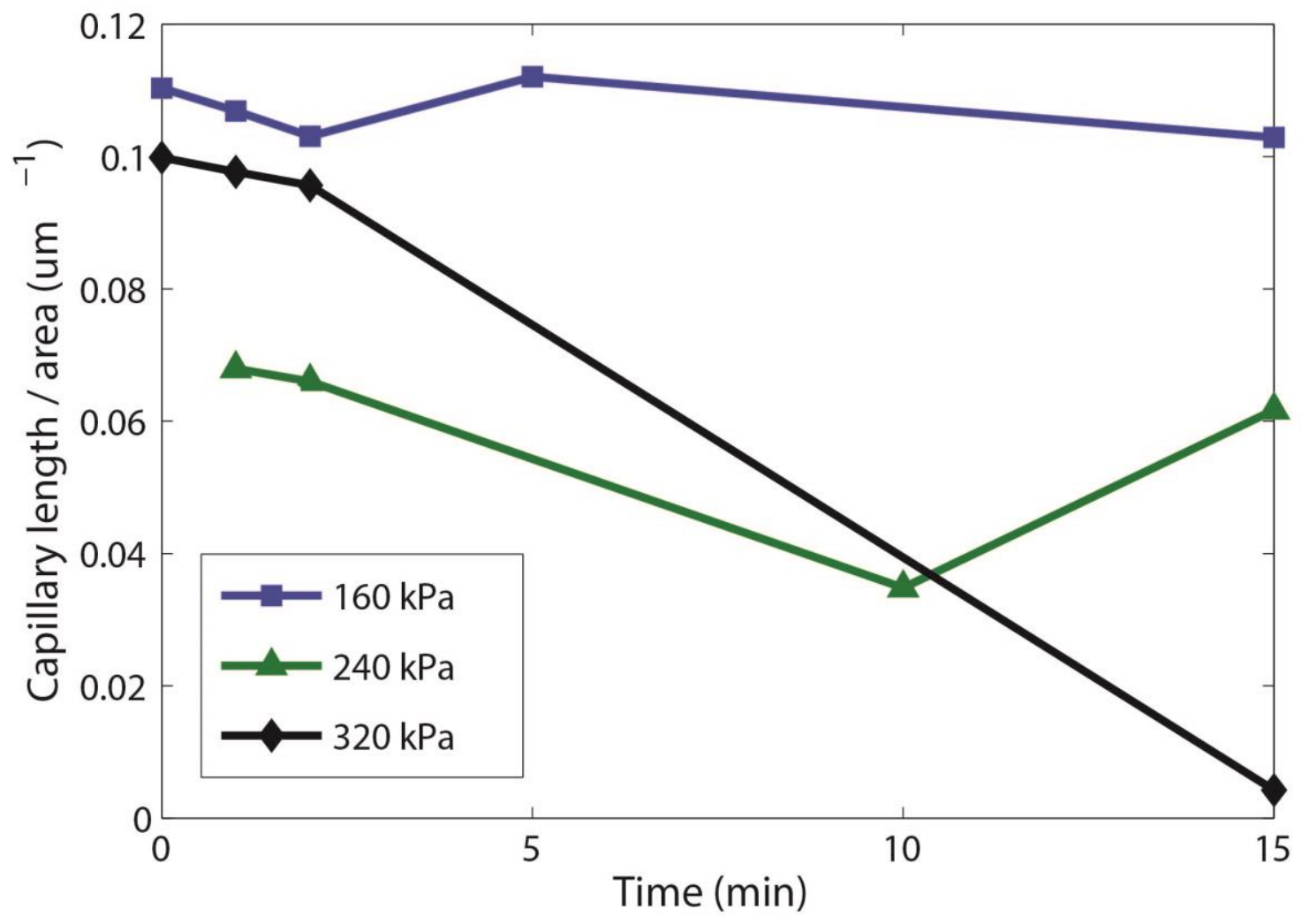

Figure 4.7 Capillary perfusion through time due to ultrasound treatment at varying exposure pressure 


\section{Discussion}

This case study showed microvascular perfusion effects caused by ultrasound and microbubbles in vivo. The perfusion effects observed throughout this study include no visible perfusion change, a temporary perfusion decrease, and a complete vascular shutdown. As expected, the effects became more severe as the acoustic pressure increased.

It was observed that occasionally the blood in the treated area appeared clumped and got stuck at a bifurcation within the vasculature which limited perfusion in adjacent areas (Figure 4.5). One of the well-known bioeffects of ultrasound which have been studied since Harvey (Harvey, 1930) is red blood cell lysis. Further studies of ultrasound bioeffects include thrombus formation which was observed by Williams (Williams, 1977) using an $85 \mathrm{kHz}$ horn tip to generate the ultrasound wave in a mouse mesentery. Ultrasound contrast agents lower the threshold for bioeffects allowing damage to occur at lower exposure pressures (Dalecki, 2004; Miller and Gies, 2000; Ter Haar, 2002).

In vivo, microbubbles are typically injected intravenously allowing them to interact primarily with the endothelial cells of the microvasculature. Considering microbubble behavior is highly dependent on their environment, the vessels and capillaries create a physical barrier that dampens microbubble oscillations (Thomas et al., 2013). Due to the microbubble behavior dependence on its surroundings, acoustic parameters need to be adjusted to account for the structural rigidity and the target vessel size. After microbubbles are ultrasonically destroyed in a region of interest, the blood flow allows for microbubbles to re-circulate into perfused treatment areas. If the perfusion is compromised early in the treatment, drug delivery or subsequent ultrasound treatments will also be limited. 
At the lowest pressure used, $160 \mathrm{kPa}$, there was no perfusion change detected within the 15 minute observation time. Although it is possible for the effect to be delayed more than 15 minutes, it is more likely that the lack of perfusion change is due to an insufficient pressure or insufficient microbubble concentration within the treatment area. Other bioeffects such as minor vascular leakage may have occurred without causing noticeable perfusion changes (Li et al., 2004; Price et al., 1998; Sheikov et al., 2004; Skyba et al., 1998; Stieger et al., 2007).

The highest pressure used, $320 \mathrm{kPa}$, caused microvascular damage that did not recover within the 15 minute observation period. In addition, the treated area appeared to decrease in size as seen by the larger microvasculature surrounding the region of interest coming closer together (Figure 4.6). This could be due to the high mechanical damage caused by the microbubble cavitation leading to physical damage of the capillaries; compromising their structure and preventing blood cells from flowing. Visually, non-perfused areas appeared dark causing vascular integrity to be difficult to assess. The results from this study agree with previous studies that have reported USMB induced vascular damage including capillary ruptures, hemorrhage and erythrocyte extravasation that increase in severity along with the acoustic power (Ay et al., 2001; Wible Jr et al., 2002).

Reversible capillary perfusion was seen at $240 \mathrm{kPa}$ where blood flow decreased but partially recovered within 15 minutes. Similar transient vascular damage has previously been reported for blood brain barrier vasculature resulting in erythrocyte extravasation (McDannold et al., 2012; Shang et al., 2011; Sheikov et al., 2008). The results shown in this study suggest one mechanism of blood flow restriction is through a temporary vascular blockage. This could be due to temporary red blood cell aggregation. Acoustic research is currently in progress to use USMB 
for thrombolysis (Frenkel et al., 2006; Porter and Xie, 2001) however the results from this study indicate that USMB may also cause temporary thrombus formation.

Differences in bioeffects between the CAM tested can be due to multiple reasons including intravascular pressure, vessel diameter, blood flow rate, vascular integrity and vascular structure. Blood flow changes can potentially alter the microbubble concentration and behavior within the acoustic field which in turn modifies the bioeffects (McDannold et al., 2011). In addition, the capillary elasticity can affect the microbubble response and the inertial cavitation threshold (Martynov et al., 2009; Sassaroli and Hynynen, 2005).

The CAM model is not without its limitations. The capillary bed is a two dimensional model and simplifies the microbubble interaction to primarily the blood and endothelial cells of the vasculature. Rather than cells and tissue surrounding the vasculature, the CAM is held together with a collagenous matrix. This simplified model of microbubble interaction with endothelial cells has a clear advantage in vascular visualization. In future studies a tumor can be grown and treated on the CAM to further study blood flow changes in tumor vasculature.

The preliminary results indicate that microvascular exposure to ultrasound and microbubbles using the CAM model can affect microvascular perfusion and result in a permanent change, a transient change that recovers within minutes, or no visible difference. The effect becomes more severe as ultrasound exposure pressure increases. Additional studies are needed to correlate the microbubble response with microvascular perfusion to determine the effect on drug delivery. 


\subsection{References}

Ay, T., Havaux, X., Van Camp, G., Campanelli, B., Gisellu, G., Pasquet, A., Denef, J.-F., Melin, J.A., Vanoverschelde, J.-L.J., 2001. Destruction of contrast microbubbles by ultrasound effects on myocardial function, coronary perfusion pressure, and microvascular integrity. Circulation 104, 461-466.

Baluk, P., Morikawa, S., Haskell, A., Mancuso, M., McDonald, D.M., 2003. Abnormalities of basement membrane on blood vessels and endothelial sprouts in tumors. Am. J. Pathol. $163,1801-1815$.

Carmeliet, P., Jain, R.K., 2000. Angiogenesis in cancer and other diseases. Nature 407, 249-257.

Dalecki, D., 2004. Mechanical bioeffects of ultrasound. Annu Rev Biomed Eng 6, 229-248.

Ferrara, K., Pollard, R., Borden, M., 2007. Ultrasound microbubble contrast agents: Fundamentals and application to gene and drug delivery.

Frenkel, V., Oberoi, J., Stone, M., Park, M., Deng, C., Wood, B., Neeman, Z., Horne, M., Li, K., 2006. Pulsed high-intensity focused ultrasound enhances thrombolysis in an in vitro model. Radiology 239, 86-93.

Gourgou, E., Aggeli, I.-K., Beis, I., Gaitanaki, C., 2010. Hyperthermia-induced Hsp70 and MT20 transcriptional upregulation are mediated by p38-MAPK and JNKs in Mytilus galloprovincialis (Lamarck); a pro-survival response. J. Exp. Biol. 213, 347-357.

Habash, R.W.Y., Bansal, R., Krewski, D., Alhafid, H.T., 2006. Thermal therapy, Part 1: An introduction to thermal therapy. Crit. Rev. Biomed. Eng. 34, 459-489.

Harvey, E.N., 1930. Biological aspects of ultrasonic waves, a general survey. Biol. Bull. 59, 306-325.

Hashizume, H., Baluk, P., Morikawa, S., McLean, J.W., Thurston, G., Roberge, S., Jain, R.K., McDonald, D.M., 2000. Openings between defective endothelial cells explain tumor vessel leakiness. Am. J. Pathol. 156, 1363-1380.

Hernot, S., Klibanov, A.L., 2008. Microbubbles in ultrasound-triggered drug and gene delivery. Adv. Drug Deliv. Rev. 60, 1153-1166.

Hirokawa, T., Karshafian, R., Pavlin, C.J., Burns, P.N., 2007. Insonation of the Eye in the Presence of Microbubbles Preliminary Study of the Duration and Degree of Vascular Bioeffects - Work in Progress. J. Ultrasound Med. 26, 731-738.

Hu, Y., Wan, J.M.F., Yu, A.C.H., 2013. Membrane Perforation and Recovery Dynamics in Microbubble-Mediated Sonoporation. Ultrasound Med. Biol. 39, 2393-2405.

Jain, R.K., Booth, M.F., 2003. What brings pericytes to tumor vessels? J. Clin. Invest. 112, 1134-1136.

Karshafian, R., Bevan, P.D., Williams, R., Samac, S., Burns, P.N., 2009. Sonoporation by Ultrasound-Activated Microbubble Contrast Agents: Effect of Acoustic Exposure Parameters on Cell Membrane Permeability and Cell Viability. Ultrasound Med. Biol. 35, 847-860.

Lang, D., Hubrich, A., Dohle, F., Terstesse, M., Saleh, H., Schmidt, M., Pauels, H.-G., Heidenreich, S., 2000. Differential expression of heat shock protein 70 (hsp70) in human monocytes rendered apoptotic by IL-4 or serum deprivation. J. Leukoc. Biol. 68, 729736.

Li, P., Armstrong, W.F., Miller, D.L., 2004. Impact of myocardial contrast echocardiography on vascular permeability: Comparison of three different contrast agents. Ultrasound Med. Biol. 30, 83-91. 
Martynov, S., Stride, E., Saffari, N., 2009. The natural frequencies of microbubble oscillation in elastic vessels. J. Acoust. Soc. Am. 126, 2963-2972.

McDannold, N., Arvanitis, C.D., Vykhodtseva, N., Livingstone, M.S., 2012. Temporary disruption of the blood-brain barrier by use of ultrasound and microbubbles: safety and efficacy evaluation in rhesus macaques. Cancer Res. 72, 3652-3663.

McDannold, N., Zhang, Y., Vykhodtseva, N., 2011. Blood-brain barrier disruption and vascular damage induced by ultrasound bursts combined with microbubbles can be influenced by choice of anesthesia protocol. Ultrasound Med. Biol. 37, 1259-1270.

Miller, D.L., Gies, R.A., 2000. The influence of ultrasound frequency and gas-body composition on the contrast agent-mediated enhancement of vascular bioeffects in mouse intestine. Ultrasound Med. Biol. 26, 307-313.

Morikawa, S., Baluk, P., Kaidoh, T., Haskell, A., Jain, R.K., McDonald, D.M., 2002. Abnormalities in pericytes on blood vessels and endothelial sprouts in tumors. Am. J. Pathol. 160, 985-1000.

Nylandsted, J., Brand, K., Jäättelä, M., 2000. Heat shock protein 70 is required for the survival of cancer cells. Ann. N. Y. Acad. Sci. 926, 122-125.

Porter, T.R., Xie, F., 2001. Ultrasound, microbubbles, and thrombolysis. Prog. Cardiovasc. Dis. 44, 101-110.

Price, R.J., Skyba, D.M., Kaul, S., Skalak, T.C., 1998. Delivery of colloidal particles and red blood cells to tissue through microvessel ruptures created by targeted microbubble destruction with ultrasound. Circulation 98, 1264-1267.

Ravagnan, L., Gurbuxani, S., Susin, S.A., Maisse, C., Daugas, E., Zamzami, N., Mak, T., Jäättelä, M., Penninger, J.M., Garrido, C., Kroemer, G., 2001. Heat-shock protein 70 antagonizes apoptosis-inducing factor. Nat. Cell Biol. 3, 839-843.

Raymond, S.B., Skoch, J., Hynynen, K., Bacskai, B.J., 2007. Multiphoton imaging of ultrasound/Optison mediated cerebrovascular effects in vivo. J. Cereb. Blood Flow Metab. 27, 393-403.

Ruchalski, K., Mao, H., Li, Z., Wang, Z., Gillers, S., Wang, Y., Mosser, D.D., Gabai, V., Schwartz, J.H., Borkan, S.C., 2006. Distinct hsp70 domains mediate apoptosis-inducing factor release and nuclear accumulation. J. Biol. Chem. 281, 7873-7880.

Rylander, M.N., Feng, Y., Bass, J., Diller, K.R., 2005. Thermally induced injury and heat-shock protein expression in cells and tissues. Ann. N. Y. Acad. Sci. 1066, 222.

Sassaroli, E., Hynynen, K., 2005. Resonance frequency of microbubbles in small blood vessels: a numerical study. Phys. Med. Biol. 50, 5293.

Schomann, T., Qunneis, F., Widera, D., Kaltschmidt, C., Kaltschmidt, B., 2013. Improved method for Ex Ovo -cultivation of developing chicken embryos for human stem cell xenografts. Stem Cells Int.

Shang, X., Wang, P., Liu, Y., Zhang, Z., Xue, Y., 2011. Mechanism of low-frequency ultrasound in opening blood-tumor barrier by tight junction. J. Mol. Neurosci. 43, 364-369.

Sheikov, N., McDannold, N., Sharma, S., Hynynen, K., 2008. Effect of focused ultrasound applied with an ultrasound contrast agent on the tight junctional integrity of the brain microvascular endothelium. Ultrasound Med. Biol. 34, 1093-1104.

Sheikov, N., McDannold, N., Vykhodtseva, N., Jolesz, F., Hynynen, K., 2004. Cellular mechanisms of the blood-brain barrier opening induced by ultrasound in presence of microbubbles. Ultrasound Med. Biol. 30, 979-989. 
Skyba, D.M., Price, R.J., Linka, A.Z., Skalak, T.C., Kaul, S., 1998. Direct in vivo visualization of intravascular destruction of microbubbles by ultrasound and its local effects on tissue. Circulation 98, 290-293.

Stieger, S.M., Caskey, C.F., Adamson, R.H., Qin, S., Curry, F.-R.E., Wisner, E.R., Ferrara, K.W., 2007. Enhancement of Vascular Permeability with Low-Frequency Contrastenhanced Ultrasound in the Chorioallantoic Membrane Model 1. Radiology 243, 112121.

Ter Haar, G.R., 2002. Ultrasonic contrast agents: safety considerations reviewed. Eur. J. Radiol. $41,217-221$.

Thomas, D.H., Sboros, V., Emmer, M., Vos, H., Jong, N., 2013. Microbubble oscillations in capillary tubes. IEEE Trans. Ultrason. Ferroelectr. Freq. Control 60, 105-114.

Tomizawa, M., Ebara, M., Saisho, H., Sakiyama, S., Tagawa, M., 2001. Irradiation with ultrasound of low output intensity increased chemosensitivity of subcutaneous solid tumors to an anti-cancer agent. Cancer Lett. 173, 31-35.

Tran, W.T., Iradji, S., Sofroni, E., Giles, A., Eddy, D., Czarnota, G.J., 2012. Microbubble and ultrasound radioenhancement of bladder cancer. Br. J. Cancer 107, 469-476.

Unger, E.C., Porter, T., Culp, W., Labell, R., Matsunaga, T., Zutshi, R., 2004. Therapeutic applications of lipid-coated microbubbles. Adv. Drug Deliv. Rev. 56, 1291-1314.

Vykhodtseva, N., McDannold, N., Hynynen, K., 2007. Effects of high intensity focused ultrasound on the brain. Presented at the 6th International Symposium on Therapeutic Ultrasound, AIP Publishing, pp. 535-541.

Wang, S., Diller, K.R., Aggarwal, S.J., 2003. Kinetics study of endogenous heat shock protein 70 expression. J. Biomech. Eng. 125, 794-797.

Wible Jr, J.H., Galen, K.P., Wojdyla, J.K., Hughes, M.S., Klibanov, A.L., Brandenburger, G.H., 2002. Microbubbles induce renal hemorrhage when exposed to diagnostic ultrasound in anesthetized rats. Ultrasound Med. Biol. 28, 1535-1546.

Williams, A.R., 1977. Intravascular mural thrombi produced by acoustic microstreaming. Ultrasound Med. Biol. 3, 191-203.

Zhong, W., Sit, W.H., Wan, J.M.F., Yu, A.C.H., 2011. Sonoporation induces apoptosis and cell cycle arrest in human promyelocytic leukemia cells. Ultrasound Med. Biol. 37, 21492159.

Zhou, F., Xing, D., Chen, W.R., 2008. Dynamics and mechanism of HSP70 translocation induced by photodynamic therapy treatment. Cancer Lett. 264, 135-144. 